\title{
LA EFICACIA EXIMENTE DE LOS PROGRAMAS DE PREVENCIÓN DE DELITOS
}

\author{
José L. González Cussac ${ }^{1}$
}

Resumen: El art. 31 bis Código Penal español atribuye eficacia eximente o atenuante de la responsabilidad penal de la persona jurídica a los programas de prevención de delitos. Pero esta eficacia no es automática, sino que requiere la concurrencia de una serie de condiciones. Así, si el delito de referencia fue cometido por un representante, administrador o directivo, se precisa, conforme al art. 31 bis 2, el cumplimiento de cuatro condiciones. Por el contrario, si el delito de referencia fue cometido por un subordinado, solo se exige explícitamente una condición de acuerdo al art. 31 bis 4 . Por su parte, las sociedades de pequeñas dimensiones presentan un régimen parcialmente singular en esta materia.

Por último, advertir que no deben confundirse las condiciones requeridas legalmente para eximir o atenuar, con los requisitos de los programas descritos en el art. 31 bis 5 .

Recibido: mayo 2019. Aceptado: octubre 2019

1 Catedrático de Derecho Penal.

Departamento de Derecho Penal. Facultad de Derecho de la Universidad de Valencia. Avda. dels Tarongers, s/n, 46022, Valencia. Email: jose.cussac@ uv.es 
Palabras clave: Responsabilidad penal personas jurídicas. Programas de prevención. Eximente. Condiciones.

\title{
THE EFFICIENCY AS EXEMPTION OF THE CRIMINAL COMPLIANCE PROGRAM
}

\begin{abstract}
Art. 31 bis) Spanish Penal Code, considers the criminal compliance programs as exemptions or a mitigating factors of corporate criminal liability. However this efficiency as exemption or mitigating circumstances is not automatic, it demands the adittion of several conditions. Thus, if an offence given was comitted by a representative, manager or executive, it is necessary, pursuant to art. 31 bis) $2 \mathrm{PC}$, the fulfillment of four conditions. Unlike this case, if an offence given, was committed by those subject to the authority of former individuals, it is only required a condition, pursuant to art. 31 bis) 4 PC. On the other hand, corporations of small size, have a regulation partially particular in this matter.

In the last place, it is necessary to notice that the conditions required legally in order to exempt or mitigate criminal liability, should not be confused with the requirements of the criminal compliance programs pursuant to art. 31 bis) 5 PC.
\end{abstract}

Keywords: Corporate criminal liability. Compliance programs. Efficiency. Exemption. Conditions.

\section{Planteamiento}

La mayor novedad de la LO 1/2015 en esta materia es la introducción en el art. 31 bis de la eximente o atenuante de la responsabilidad penal de la persona jurídica, consistente en que la sociedad se haya dotado y desarrollado un "modelo de organización y prevención". Es decir, se articula un mecanismo de exoneración o disminución de la responsabilidad penal de la empresa si posee un programa de cumplimiento.

Pero el texto distingue entre las condiciones de los programas (art. 31 bis $2^{\circ}, 3^{\circ}$ y $4^{\circ}$ ) y los requisitos que han de revestir los programas (art. 31 bis $5^{\text {a }}$ ). En este trabajo analizaremos 
seguidamente ambos desde una interpretación del texto de la ley española. Para que los citados programas desplieguen su eficacia eximente o atenuante los jueces deben comprobar y valorar jurídicamente el cumplimiento de estas exigencias legales.

Respecto a las condiciones que han de reunir los programas de cumplimiento para desplegar su eficacia eximente o atenuante, el CP las diferencia y estructura en tres grupos diferentes, en atención a dos criterios. El primer criterio obedece al sujeto persona física que comete el delito de referencia, de suerte que establece dos tipos de condiciones, una para representantes, directivos y administradores (art. 31 bis $2 \mathrm{CP}$ ), y otras condiciones si el delito de referencia fue cometido por un subordinado (art. 31 bis $4^{\circ} \mathrm{CP}$ ). Un segundo criterio estipula unas condiciones específicas en consideración a la dimensión o tamaño de la sociedad (art. 31 bis $3 \mathrm{CP}$ ).

Pero antes de llegar al examen de validez de las condiciones y requisitos del programa de cumplimiento, los jueces y tribunales deben haber verificado la concurrencia de los "presupuestos comunes" y de los "hechos de conexión" establecidos en la ley², como explícitamente se desprende del texto vigente ${ }^{3}$.

El Código Penal exige siempre y en todo caso la comprobación de tres presupuestos comunes para poder castigar penalmente a una sociedad. Sintéticamente estos tres presupuestos son los siguientes: a) la previa actuación ilícita del sujeto persona física que legalmente se considera idóneo para desencadenar el proceso de transferencia de responsabilidad ${ }^{4}$; b) que

2 Con otros términos pero en sentido similar FERNÁNDEZ TERUELO, J.: Responsabilidad penal de las personas jurídicas: Requisitos comunes a los criterios de transferencia o conexión o doble vía de imputación [art. 31 bis, apartados a) y b)]", en "Corrupción y prevención de delitos de corrupción" (A. Matallín Evangelio Dir.), Valencia (Tirant lo Blanch) 2018, pags. 43 y ss.

3 En este sentido GONZÁLEZ CUSSAC, J. L.: "¿Sobre qué han de decidir los jueces penales?", en Tratamiento penal de la persona jurídica, Curso de Formación Continua de Fiscales (código FCO280VC), CEJ, Madrid, 24 a 26 de septiembre 2018.

4 En la STS 742/2018, de 7 febrero 2019, se advierte expresamente que "una cosa es que se exija la 'constatación' de la actuación de esos sujetos per- 
el delito cometido por la persona física se encuentre dentro de los delitos que expresamente la ley habilita para poder transferir la responsabilidad a la persona jurídica $\left.{ }^{5}, y, c\right)$ que la sociedad posea personalidad jurídica.

Una vez comprobados los tres presupuestos comunes, el art. 31 bis describe dos diferentes hechos de conexión para habilitar el mecanismo de transferencia de responsabilidad penal desde la actuación ilícita de algunas personas físicas hasta la persona jurídica. Es decir, contempla dos posibles y diferentes "hechos de conexión" en consideración al rango y facultades de las personas físicas que cometieron el delito de referencia ${ }^{6}$.

El primer hecho de conexión es el descrito en el apartado 1 a) del art. 31 bis CP, donde se definen personas físicas con poder y representación societaria de máxima autoridad y nivel que, al cometer un delito, desencadenan la transferencia de responsabilidad criminal (representantes, directivos y administradores).

Y el segundo hecho de conexión, desarrollado en el apartado 1 b) del art. 31 bis $\mathrm{CP}$, se refiere a la actuación ilícita de personas físicas que están sometidas a la autoridad de las antes referidas, y que han incumplido gravemente sus obligaciones de vigilancia y control (subordinados $)$.

Por tanto, la primera clave en el análisis de la responsabilidad penal de una sociedad en el marco legal español es constatar si concurren los presupuestos de transferencia y luego uno de los hechos de conexión contenido en la ley. Esto es, los que

sonas fisicas y otra que sea un presupuesto la previa 'condena' de las mismas" $\left(\mathrm{FJ} 2^{\circ}\right.$ ).

5 La STS 123/2019, de 8 marzo 2019, requiere como presupuesto inicial de la responsabilidad penal de la persona jurídica "la comisión de alguno de los delitos que se señalan en la parte especial del Código Penal como imputables a las mismas", junto al presupuesto de que su comisión haya sido realizada por alguna de las personas y en las condiciones establecidas en el art. 31 bis y siguientes del CP.

6 Cfr. ROSAL BLASCO, B., Del, "La delimitación típica de los llamados hechos de conexión en el nuevo artículo 31 bis, $n^{\circ} 1$, del Código Penal", Cuadernos de Política Criminal, Segunda Época, nº 103, 2011. 
permiten conectar, en el sentido de atribuir, derivar, o transferir la responsabilidad penal desde la persona natural a la persona moral. Este conjunto de presupuestos y hechos de conexión legalmente requeridos para poder condenar a una persona jurídica, unos autores los denominan "hechos de conexión" y otros "hecho propio" de la persona jurídica.

De modo que el texto penal vigente puede decirse que contiene dos modelos concurrentes de responsabilidad penal de las personas jurídicas. El primero, en los supuestos en los que el delito de referencia es cometido por un representante, directivo o administrador. A este primer modelo originado en el art. 31 bis 1 , a) CP, corresponde a su vez un régimen de condiciones necesarias para que su programa de cumplimiento pueda operar como eximente o atenuante de la responsabilidad penal de la persona jurídica, y es el regulado en el art. 31 bis 2 CP. Por su parte, el segundo modelo se origina en casos donde el delito de referencia es cometido por un subordinado, estando regulado en el art. 31 bis 1 b). A este hecho de conexión le corresponde también un régimen diferente de condiciones necesarias para que, si posee un programa de cumplimiento, pueda tener eficacia eximente o atenuante.

Así pues, a cada uno de los dos hechos de conexión estipulados en el art. 31 bis 1 , el texto legal le agrega un régimen propio de condiciones necesarias para que el programa de cumplimiento pueda tener virtualidad eximente o atenuante. En síntesis, cada uno de los dos hechos de conexión tiene su propio régimen de condiciones para la exención o atenuación de la pena a la persona jurídica.

La regulación española se completa con una excepción para las empresas de pequeñas dimensiones, relativa a una de las condiciones exigidas, y ello con independencia del hecho de conexión.

En consecuencia, el debate jurídico acerca de si un programa de cumplimiento posee eficacia eximente o atenuante solo es posible después de la comprobación de los presupuestos 
y hechos de conexión, siempre que la sociedad alegue estar en posesión de un programa de cumplimiento.

Y por último, los requisitos que han de tener los programas de cumplimiento, descritos en el art. 31 bis 5, son exactamente iguales para todos los supuestos anteriores.

\section{Las condiciones para eximir de responsabilidad penal en el modelo legal español}

$\mathrm{El}$ art. 31 bis, apartados 2, 3 y 4, contiene las condiciones exigidas para que un programa despliegue su eficacia eximente o atenuante. De esta regulación se derivan dos premisas fundamentales. Primera, que la sola posesión de un programa no es suficiente para lograr la exención o atenuación de la responsabilidad penal de la persona jurídica. Y segunda, que para alcanzar la exención o atenuación el programa debe reunir todas y cada una de las condiciones exigidas legalmente. Por consiguiente, el art. 31 bis no contiene varias eximentes ni varias atenuantes, sino una sola, que para aplicarse precisa la concurrencia acumulativamente de todas ellas?.

No obstante, con carácter previo a su examen, hay que advertir que la exégesis de las condiciones se halla estrechamente vinculada al modelo legal ${ }^{8}$, fundamento y entendimiento integral del modelo de responsabilidad penal de la persona jurídica. Que a su vez enlaza con las diversas concepciones de la teoría jurídica del delito9 . Por ello ya ha suscitado múltiples propuestas

7 Así, GALÁN MUÑOZ, A.: Fundamentos y límites de la responsabilidad penal de las personas jurídicas tras la reforma de la LO 1/2015, Valencia (Tirant lo Blanch), 2017, pag. 129.

8 TIEDEMANN, K.: Responsabilidad penal de las personas jurídicas, otras agrupaciones y empresas en Derecho comparado, en La reforma de la justicia penal: (estudios en homenaje al Prof. Klaus Tiedemann) J. 1. Gómez Colomer y J. L. González Cussac coordinadores, Castellón (Publicaciones de la Universidad Jaime I), 1997, pp. 23 y ss.

9 Por ejemplo, las apuntadas por FERNÁNDEZ TERUELO, J.: Regulación vigente: exigencias legales que permiten la atribución de responsabilidad 
interpretativas ${ }^{10}$. Con la finalidad de contextualizar la discusión en un marco teórico, sintetizaré las diferentes propuestas doctrinales siguiendo una agrupación de las tantas que pueden hacerse, y que naturalmente prescinde de importantes matices de los distintos autores ${ }^{11}$.

\section{a) Modelo de negación de una auténtica responsabilidad} penal de la persona jurídica. En un primer grupo se situarían los que niegan la verdadera o auténtica naturaleza penal de esta clase de responsabilidad, proponiendo alternativas, y que GALÁN MUÑOZ califica de "discurso de resistencia" ". Se aducen

penal a la persona jurídica y estructura de imputación (CP art. 31 bis 1, 2 inciso $1^{\circ}$ y $5^{\circ}$ ), en JUANES PECES, Á. (Dir.): Responsabilidad penal y procesal de las personas jurídicas, Madrid (Francis Lefebvre), 2015, pags. 65 y ss.

10 Recientemente puede verse una exposición crítica en GALÁN MUÑOZ, A.: Fundamentos y límites de la responsabilidad penal de las personas jurídicas tras la reforma de la LO 1/2015, Valencia (Tirant lo Blanch), 2017, pags. 97 y ss; y, LEÓN ALAPONT, J.: "Criminal Compliance: análisis de los arts. 31 bis 2 a 5 CP y 31 quater CP", Revista General de Derecho Penal, $\mathrm{n}^{\circ} 31$, mayo 2019. Desde una perspectiva más general, BUSATO, P. C.: Tres tesis sobre la responsabilidad penal de las personas jurídicas, Valencia (Tirant lo Blanch), 2019, pags. 77 y ss.

11 GALÁN MUÑOZ, A.: Fundamentos y limites de la responsabilidad penal de las personas jurídicas.., cit, pags. 176 y ss., propone la siguiente clasificación de posturas doctrinales tras la reforma de 2015: a) Un sistema de responsabilidad de la persona jurídica por hecho ajeno, pero con culpabilidad o punibilidad propias; b) la cultura de cultura defectuosa de cumplimiento normativo como fundamento; $y, c)$ la existencia de defectos organizativos como fundamento del injusto propio. Un resumen doctrinal de posturas a favor y en contra de la introducción legal del modelo puede verse en BOLDOVA PASAMAR, M. A.: "La introducción de la responsabilidad penal de las personas jurídicas en la legislación española”, Estudios Penales y Criminológicos, XXXIII, 2013. Cfr. también DÍAZ y GARCÍA CONLLEDO, M.: “¿Responsabilidad penal de las personas jurídicas? Algunas tesis”, Libertas, Revista de la Fundación Internacional de Ciencias Penales, $\mathrm{n}^{\circ} 5$, 2016, pags. 31 a 43.

12 GALÁN MUÑOZ, A.: "Fundamentos y límites de la responsabilidad penal de las personas jurídicas tras la reforma de la LO 1/2015", Valencia (Tirant lo Blanch), 2017, pags., 48 y ss.; y, 112 y ss. 
motivos constitucionales, pero sobre todo dogmáticos, incluidos los esgrimidos desde la teoría de la norma ${ }^{13}$.

b) Modelo de heterorresponsabilidad limitada. Así se enmarca a quienes otorgan mayor relevancia a la conducta previa de la persona física, lo que para sus críticos comporta fundamentar la responsabilidad de la persona jurídica en un hecho ajeno. No obstante, los adscritos a esta propuesta, consideran que el texto legal vigente obliga a partir del delito cometido por una persona natural, por lo que el recurso a nociones como el "defecto de organización" y la "cultura de cumplimiento", no solo no se contienen en la literalidad del art. 31 bis CP, sino que además constituyen nociones vagas, indeterminadas e inciertas. Estas nociones pueden tener valor solo a efectos de lege ferenda o de justificaciones político-criminales. Añaden que los intentos por construir una culpabilidad propia solo son ficciones para ocultar precisamente su conculcación. Por ello aducen que su fundamento no descansa en una verdadera culpabilidad de la persona moral, sino en una "responsabilidad especial amplia$d a$ ", de naturaleza objetiva, por el peligro que asume en virtud del riesgo permitido en su actividad social ${ }^{14}$.

13 Representante de este discurso, entre otros, GRACIA MARTÍN, L.: "Critica a las modernas construcciones desde una mal llamada responsabilidad penal de la persona jurídica", RECPC, 18-05, 2016. Desde otros planteamientos, CIGÜELA SOLA, J.: La culpabilidad colectiva en el derecho penal. Crítica y propuesta de una responsabilidad estructural de la empresa, Madrid (Marcial Pons), 2015. Con ironía, GALÁN MUÑOZ se refiere a estos autores como "esos irreductibles germanos"; en Fundamentos y limites de la responsabilidad penal de las personas jurídicas ..., cit. pags. 48 y ss.

14 En estos términos, DEL ROSAL BLASCO, B.: "Sobre los elementos estructurales de la responsabilidad penal de las personas jurídicas: reflexiones sobre las SSTS 154/2016 y 221/2016 y sobre la Circular núm. 1/2016 de la Fiscalía General del Estado", La Ley, núm. 8732, 2016. Próximo a esta exégesis, LEÓN ALAPONT, J.: "Criminal Compliance: análisis de los arts. 31 bis 2 a 5 CP y 31 quater CP”, Revista General de Derecho Penal, $n^{\circ} 31$, mayo 2019; LEÓN ALAPONT, J.: La responsabilidad penal de los partidos políticos, Valencia (Tirant lo Blanch), 2019, pags. 278 y ss. Muy cercana a esta línea ROBLES PLANAS, R.: 'El 'hecho propio' de las personas jurídicas y el Informe del Consejo General del Poder Judicial al Anteproyecto de Reforma del Código Penal de 2008", InDret, n² 2, 2009. Dentro de 
c) Modelo de responsabilidad por participación omisiva e imprudente. Esta es la tesis de RODRÍGUEZ RAMOS, que entiende que la responsabilidad penal de la persona jurídica se sustenta en una participación objetiva a título de cooperación necesaria en comisión por omisión de los delitos cometidos por la persona física. Por su parte, la imputación subjetiva, descartada por imposible la modalidad dolosa, se sustenta en la imprudencia, en la medida que la conducta delictiva de la personas natural habría resultado previsible y evitable si hubiesen funcionado correctamente las medidas de vigilancia y control ${ }^{15}$.

Merece la pena traer aquí a colación el calificativo de "gatopardiano" para las anteriores posturas doctrinales. Ha sido usado por GALÁN MUÑOZ, porque a su juicio, lo merecen tanto los diversos pronunciamientos jurisprudenciales y de la Fiscalía General del Estado, como los distintos autores que, en mayor o menor medida, no toman suficientemente en consideración los cambios introducidos en la reforma de 2015, y siguen aferrados a sus convencimientos iniciales o al texto de $2010^{16}$.

d) Modelo de autorresponsabilidad absoluta. En la doctrina también se ha formulado una tesis novedosa exclusivamente creada para explicar la responsabilidad criminal de la persona moral. Se trata de construir una responsabilidad penal propia de la persona jurídica, totalmente diferenciada de la responsabilidad penal de las personas físicas, y que por tanto goza de un fundamento distinto e independiente. En la misma se distingue entre el injusto propio de la persona moral, construido en la noción de "defecto de organización", y una culpabilidad propia de la misma, que descansa en el parámetro de una "cultura de incumplimiento de la legalidad". Solo desde un injusto y culpabilidad

esta línea interpretativa debe ubicarse tanto la Circular 1/2016 de la Fiscalía General del Estado, como los siete votos particulares contenidos en la STS 154/2916, de 29 febrero.

15 RODRÍGUEZ RAMOS, L.: "Sobre la culpabilidad de las personas jurídicas", Diario La Ley, n 8766, 2016

16 GALÁN MUÑOZ, A.: Fundamentos y límites de la responsabilidad penal de las personas jurídicas..., cit. pags. 97 y ss. 
propia y autónoma de la de la persona física es constitucionalmente sostenible la responsabilidad penal del ente colectivo. Por ello consideran que los sistemas de heterorresponsabilidad son incompatibles con los principios básicos del Derecho penal ${ }^{17}$.

e) Modelo de autorresponsabilidad limitado. Es el sostenido por la doctrina mayoritaria, que desde diversas premisas, comparten la preocupación por erradicar una culpabilidad objetiva o por hecho ajeno y consecuentemente también tratan, desde el texto vigente, ofrecer un fundamento autónomo de la culpabilidad de la persona jurídica. Para ello consideran necesario para la declaración de responsabilidad penal de una persona moral comprobar dos planos: a) la imputación objetiva, en donde se incluyen lo que aquí he denominado presupuestos y hechos de conexión; $\mathrm{y}, \mathrm{b}$ ) la imputación subjetiva, o si se prefiere la culpabilidad de la persona jurídica, reflejada en la ausencia de medidas idóneas orientadas a la prevención de comisión de delitos en su seno, esto es, en un "defecto de organización"18.

17 Esta es la tesis elaborada por GÓMEZ-JARA DÍEZ, C.: Fundamentos de la responsabilidad penal de las personas jurídicas, en BAJO FERNÁNDEZ, M.; FEIJÓO SÁNCHEZ, B. y GÓMEZ-JARA DÍEZ, C.: Tratado de responsabilidad penal de las personas jurídicas, Pamplona (Cizur Menor, Thomson Reuters-Aranzadi), 2016, pp. 105-106. Del mismo autor El injusto típico de la persona jurídica (tipicidad), en BAJO FERNÁNDEZ, M.; FEIJÓO SÁNCHEZ, B. y GÓMEZ-JARA DÍEZ, C.: Tratado de responsabilidad penal de las personas jurídicas, Pamplona (Cizur Menor, Thomson Reuters-Aranzadi), 2016, p. 128; del mismo: El Tribunal Supremo ante la responsabilidad Penal de las Personas Jurídicas. El inicio de una larga andadura, Pamplona (Thomson Reuters-Aranzadi), 2017. Muy cercano a esta tesis se encuentra, aunque con algunos matices, la propuesta de FEIJÓO SÁNCHEZ, B.: El delito corporativo en el Código penal español, Pamplona (Cizur Menor, Thomson Reuters-Aranzadi), 2015. Igualmente cercano, pero también con matices, GONZÁLEZ SIERRA, P.: La imputación penal de las personas jurídicas, Valencia (Tirant lo Blanch), 2014. En esta dirección habría que situar el voto mayoritario contenido en la STS (de Pleno) 154/2016, de 29 febrero y también parcialmente en la STS 516/2016, de 13 de junio.

18 Así, entre otros: AGUDO FERNÁNDEZ, E.; JAÉN VALLEJO, M. y PERRINO PÉREZ, Á. L.: Derecho penal de las personas jurídicas, Madrid, Dykinson, 2016, p. 45; BACIGALUPO SAGESSE, S.: Artículo 31 bis, ter, 
En este grupo puede adscribirse con matices la propuesta de GALÁN MUÑOZ, que, desde la lectura del texto legal, propone la idea a de prevención como fundamento de la responsabilidad penal de la persona jurídica por el concreto delito cometido. Para ello parte de un deber genérico de prevenir delitos impuesto por el Derecho al ente colectivo, a todos sus integrantes, que establece una cadena de deberes establecidos en el Código penal. Y, al infringirse dicho mandato, se produce una aportación delictiva que se podía y debía haber evitado de forma colectiva ${ }^{19}$.

Ante este panorama varios autores han subrayado que, ni se puede afirmar que la doctrina sea pacífica al concebir el

quater, quinquies, en GÓMEZ TOMILLO, M. (Dir.): Comentarios prácticos al Código penal. Tomo I, Cizur Menor, Thomson Reuters-Aranzadi, 2015, p. 475; FERNÁNDEZ TERUELO, J.: Regulación vigente: exigencias legales que permiten la atribución de responsabilidad penal a la persona jurídica y estructura de imputación (CP art. 31 bis 1, 2 inciso $1^{\circ}$ y $5^{\circ}$ ), en JUANES PECES, Á. (Dir.): Responsabilidad penal y procesal de las personas jurídicas, Madrid (Francis Lefebvre), 2015, p. 79; GÓMEZ TOMILLO, M.: Introducción a la responsabilidad penal de las personas jurídicas, Pamplona (Cizur Menor, Thomson Reuters-Aranzadi), 2015, pp. 78 y 134; DE LA MATA BARRANCO, N. J.: La actuación conforme a protocolos de prevención de delitos como causa de exención de responsabilidad penal, en DE LA CUESTA ARZAMENDI, J. L. (Dir.): Responsabilidad Penal de las Personas Jurídicas, Pamplona (Cizur Menor, Thomson Reuters-Aranzadi), 2013, p. 253; NIETO MARTÍN, A.: "La responsabilidad penal de las personas jurídicas: un modelo legislativo”, Madrid, Iustel, 2008, p. 146; ORTIZ DE URBINA GIMENO, I.: Responsabilidad penal de las personas jurídicas. Cuestiones materiales, en AYALA GÓMEZ, I. y ORTIZ DE URBINA GIMENO, I. (Coords.): Penal económico y de la empresa 2016-2017, Madrid (Francis Lefebvre), 2016, p. 173; ZUGALDÍA ESPINAR, J. M.: La responsabilidad criminal de las personas jurídicas en el Derecho penal español (análisis de la cuestión tras la reforma operada por la LO 1/2015, de 30 de marzo), en ZUGALDÍA ESPINAR, J. M. y MARÍN DE ESPINOSA CEBALLOS, E. B. (Dir.): La responsabilidad criminal de las personas jurídicas en Latinoamérica y en España, Pamplona (Cizur Menor, Thomson Reuters-Aranzadi), 2015, p. 223; ZUGALDÍA ESPINAR, J. M.: La responsabilidad criminal de las personas jurídicas, de los entes sin personalidady sus directivos, Valencia (Tirant lo Blanch), 2013, p. 74.

19 Fundamentos y límites de la responsabilidad penal de las personas jurídicas ... cit., pags. $121 \mathrm{y}$ ss. 
modelo de responsabilidad penal de la persona jurídica, ni tampoco que exista un acuerdo en la interpretación del Código Penal vigente. No obstante, lo que también puede afirmarse es que existen bastantes puntos de acuerdo, sobre todo en lo referente a buscar una aplicación sujeta a las exigencias constitucionales. Igualmente señalar que de todas las propuestas pueden extraerse criterios interpretativos solventes en esta tan novedosa regulación. La tarea del intérprete es contribuir a fijar criterios consensuados que generen pautas estables, con el fin de alcanzar una mínima seguridad jurídica.

Mi adscripción a alguna de las anteriores propuestas se desgranará en las líneas siguientes ${ }^{20}$. No obstante, si deseo advertir que trataré de ajustarme a una metodología denominada filosofía del lenguaje y más concretamente la formulada por VIVES ANTÓN, conocida como "concepción significativa de la acción". Desde este prisma, cuando "se abandona el contexto de uso en el que cobran sentido las palabras de la ley", inevitablemente entran en juego las múltiples concepciones de la justicia material ${ }^{21}$. De suerte que, el precio de abandonar una interpretación sujeta al texto legal se paga con un incremento de la inseguridad jurídica, un debilitamiento del principio de legalidad penal y una sustitución de los mandatos contenidos en la ley por las apreciaciones de justicia material de cada aplicador.

Pues bien, en este debate coincido con BUSATO al considerar que el modelo clásico (heterorresponsabilidad) practica una espuria importación del contenido teórico del Derecho civil, con serias dudas de violación del principio de culpabilidad. Y por su parte, las propuestas modernas, sujetas al criterio del "defecto de organización", tratan sin éxito de disimular la conexión de la responsabilidad de la persona jurídica con la conducta precedente de la persona física (hechos de conexión) pero no logran

20 En particular, vid. infra 7.

21 Puede verse ampliamente en VIVES ANTÓN, T. S.: Fundamentos del sistema penal, $2^{\mathrm{a}}$ edición, Valencia (Tirant lo Blanch), y en concreto, la frase citada, en pags. 772 y 773 . 
resolver satisfactoriamente el problema de la heterorresponsabilidad $^{22}$.

Por ello, en su opinión, una verdadera autorresponsabilidad de la persona jurídica debe sustentarse en tres pilares: desvalor de acción, desvalor de resultado y culpabilidad propias $^{23}$. Así, debe imputarse una conducta realizada por ella, que se corresponda con el resultado antijurídico y que pueda serle atribuida como su propia acción, esto es, como su contribución subjetiva $^{24}$. Para lograr esta explicación, sugiere que el camino más claro es seguir el paradigma de la filosofía del lenguaje desarrollado por VIVES ANTÓN. Y más en concreto se apoya en los trabajos de CARBONELL MATEU que aplican esta concepción de la acción significativa a la responsabilidad penal de la persona jurídica ${ }^{25}$.

Analizadas las diferentes opciones doctrinales, a continuación se exponen los tres regímenes de condiciones para que un programa de cumplimiento pueda ser estimado como eximente o atenuante.

22 BUSATO, P. C.: Tres tesis sobre la responsabilidad penal de personas jurídicas, Valencia (Tirant lo Blanch), 2019, pags. 78 y ss.

23 Se aprecia una notable cercanía con la propuesta desarrollada por GALÁN MUÑOZ y expuesta antes, como próxima a un modelo de autorresponsabilidad limitada.

24 BUSATO, P. C.: Tres tesis... ", cit. 89 y ss.

25 CARBONELL MATEU, J. C.: Aproximación a la dogmática de la responsabilidad penal de las personas jurídicas, en Constitución, derechos fundamentales y sistema penal. Semblanzas y estudios con motivo del setenta aniversario del prof. Tomás S. Vives Antón (Dir. Carbonell Mateu; González Cussac; Orts Berenguer; Cuerda Arnau), Valencia (Tirant lo Blanch) 2009, p. 301 a 322; y, del mismo: "Responsabilidad penal de las personas juridicas: reflexiones en torno a su dogmática y al sistema de la reforma de 2010”, Cuadernos de Política Criminal, $2^{\mathrm{a}}$ Época, $\mathrm{n}^{\mathrm{o}} 101,2010$, pags. 5 y ss. 


\section{Condiciones si el delito de referencia fue cometido por representante, administrador o directivo, art. 31 bis 1 a), co- rresponden las condiciones del art. 31 bis 2}

En los supuestos en los que el delito de referencia fue cometido por un representante, directivo o administrador conforme al art. 31 bis 1 a), las condiciones exigidas se contienen en el art. 31 bis 2. Comenzaré con la descripción esquemática de las condiciones y a continuación con un análisis individualizado.

Condiciones del art. 31 bis $2 \mathrm{CP}$ :

- Idoneidad temporal, formal y material

- Órgano con poderes autónomos de supervisión del funcionamiento y cumplimiento del programa

- Que el delito se haya cometido eludiendo fraudulentamente los modelos de prevención.

- Que los órganos sociales hayan actuado con la diligencia debida: sin omisión o ejercicio insuficiente de sus funciones de supervisión, control y vigilancia

\subsection{Idoneidad temporal, formal y material}

El precepto literalmente dice: "el órgano de administración ha adoptado y ejecutado con eficacia, antes de la comisión del delito, modelos de organización y gestión que incluyan las medidas de vigilancia y control idóneas para prevenir delitos de la misma naturaleza o para reducir de forma significativa el riesgo de su comisión".

Del propio texto extraigo el término idoneidad como trasunto de "idóneas". Este término se halla vinculado a la exigencia de "eficaz". Por consiguiente, un programa de cumplimiento será jurídicamente "eficaz" si contiene medidas "idóneas" para prevenir o reducir el riesgo de comisión de delitos de la "misma naturaleza". Así pues, la primera condición, idoneidad, se desdobla en tres. 


\subsubsection{Idoneidad temporal}

Exige que el órgano de administración societaria haya "adoptado y ejecutado con eficacia, antes de la comisión del delito", el programa de cumplimiento. Precisa pues de una comprobación estrictamente temporal que remite a la fecha de comisión del delito cometido por la persona física. El programa de cumplimiento debe haber sido adoptado y ejecutado antes de esa fecha. Comporta dos tipos de comprobaciones. La primera, "adoptado", remite a la decisión expresa y formal del acuerdo del órgano de administración. Y "ejecutado", a la efectiva puesta en funcionamiento del programa. Si concurre la primera pero no la segunda, podría estimarse como atenuante.

\subsubsection{Idoneidad formal}

La condición de idoneidad formal requiere que el programa contemple expresamente, como actividad de riesgo, un delito de la misma naturaleza que el cometido. Del tenor literal parece deducirse que aquí bastaría comprobar que el programa incluye expresamente medidas eficaces para haber prevenido la clase de delito ("misma naturaleza") que el realmente perpetrado. Así pues precisa cotejar el delito cometido por la persona física representante, directivo o administrador y el previsto explícitamente en el programa, siempre que se trate de una de las infracciones con cláusula expresa de remisión al art. 31 bis. En realidad, la idoneidad formal apunta a una comprobación de "identidad" entre dos infracciones penales.

El empleo en el texto legal de la expresión "misma naturaleza" referida a los delitos objeto de la comparación, abre la puerta a tres exégesis: una restrictiva, otra declarativa y una tercera extensiva. La primera, una interpretación restrictiva, exigiría una estricta equivalencia entre preceptos legales específicos. La segunda, interpretación declarativa, apunta a una equivalencia algo más amplia referida a una comparación entre figuras delictivas. La tercera, interpretación extensiva, permitiría una equivalencia todavía mas amplia que la establecida entre figuras delictivas, que incluso podría desbordar el propio nomen iuris. 
Lo expongo ahora con algunos ejemplos. Es clara la identidad formal si se trata de la previsión como riesgo de una estafa genérica del art. 248, y el delito cometido es justamente ese, un supuesto indiscutible de idoneidad formal exacta (interpretación restrictiva). Pero también podría suceder que el programa de cumplimiento incluya una referencia a la estafa genérica del art. 248 y el delito cometido sea una estafa específica del art. 251. Aquí indudablemente se trata de dos delitos de la "misma naturaleza", aunque regulados en figuras legales diferentes (interpretación declarativa). Ciertamente el texto no exige, como si se hace en una operación similar en la agravante de reincidencia, que los dos delitos estén comprendidos en el mismo Título. Por tanto no es sencillo oponer este argumento sistemático en la clase de casos como el planteado, aunque en efecto no solo comparten Título sino Capítulo. Quizás más que un criterio exegético de carácter excluyente debería ser empleado como incluyente, esto es, que compartir regulación en el mismo Capítulo, o incluso Título dentro del Código Penal, refuerza compartir la "misma naturaleza", y más aun si cabe al tratarse de una condición puramente formal. Además, esta interpretación es justamente declarativa porque ofrece un ámbito de aplicación coincidente con el derivado de un uso de las palabras según el uso común del lenguaje ${ }^{26}$.

Más dudoso sería comprender "misma naturaleza" como equivalente a grandes "familias delictivas", (interpretación extensiva). Es decir, a una categoría abstracta, difusa, muy abierta y que desborda no solo el nomen iuris sino también su ubicación sistemática en el Código Penal. Es decir, una categoría no exactamente formal en el sentido de extraída directamente de la ley. Me refiero por ejemplo a la pretensión de considerar de la "misma naturaleza" a toda clase de defraudaciones (estafas, fraude fiscal, malversación como administración desleal, etc):

26 En este sentido, favorable a una interpretación que aquí hemos llamado declarativa, GALÁN MUÑOZ, A.: Fundamentos y límites de la responsabilidad penal de las personas jurídicas..., cit. pags. 130 y 131, y nota 189. 
o a cualquier delito informático (acceso ilícito, fraudes, pornografía, acoso, daños, etc), o entre los delitos de corrupción (prevaricación, cohechos, malversación, tráfico de influencias, exacciones ilegales, etc.).

No obstante, es ocioso advertir que, aunque se diera por cumplida esta condición formal, será necesario satisfacer la siguiente condición de idoneidad material, que se antoja difícil si la idoneidad formal es muy laxa. En efecto, porque al no ser exacta, solo muy remotamente podrán ser consideradas eficaces las medidas adoptadas para prevenir un delito parecido pero no idéntico al previsto en el programa.

\subsubsection{Idoneidad material}

El art. 31 bis 2, $1^{\text {a }}$ señala que los programas de cumplimento habrán de incluir "las medidas de vigilancia y control idóneas para prevenir delitos de la misma naturaleza o para reducir de forma significativa el riesgo de su comisión". De modo que la eficacia del programa de cumplimiento, desde el examen jurídico-penal que aquí interesa, esto es, de su virtualidad eximente o atenuante, obliga al juez a evaluar la "idoneidad material" de las medidas contempladas y adoptadas para prevenir delitos o reducir el riesgo de su comisión. Sin duda se trata de la operación más compleja, tanto porque lo es en sí misma, como porque se halla estrechamente vinculada con el entendimiento y fundamento del sistema de responsabilidad penal de la persona jurídica.

Por mi parte, respecto al tema que nos ocupa, me ceñiré a analizar tres cuestiones que considero esenciales. Una referida a si el texto legal contiene una o dos fórmulas de evaluación de la idoneidad. Es decir, si prevenir delitos y reducir de forma significativa el riesgo de su comisión son operaciones equivalentes, $\mathrm{o}$ si por el contrario encierran dos fórmulas diferentes de verificación. Aquí aprovecharé para ofrecer algunos criterios desde una exégesis literal del precepto (A). La segunda cuestión abordada, es la relativa al parámetro de medición de la idoneidad, que para 
unos se limita a cotejar las medidas adoptadas en relación al delito cometido, mientras que para otros debe extenderse a la totalidad del programa (B). Y la tercera versa sobre los criterios de verificación y las "fuentes de la estandarización" (C).

A) Equivalencia o diversidad de fórmulas. Previamente a esta cuestión, es necesario comenzar por el término "idóneas" (para prevenir delitos o reducir riesgos). "Idóneas" está referido a las medidas contenidas en el programa. Por consiguiente, la ley obliga al juez a practicar una valoración de carácter normativa, en la que tendrá que decidir si las medidas son idóneas, es decir, adecuadas, aptas o capaces de prevenir delitos de la misma naturaleza o reducir significativamente el riesgo de su comisión.

En mi primera lectura del texto me incliné por entender que contenía dos fórmulas diferentes, una referida al sentido del término "prevenir delitos de la misma naturaleza", y otra al de "reducir de forma significativa el riesgo de comisión" 27. ¿Es idéntico prevenir delitos que reducir los riesgos de su comisión?.

Desde luego, si entendemos ambas expresiones como idénticas, parte de la discusión habrá terminado. Pero esta salida se compadece poco con el principio de vigencia en la interpretación y además supondría entender que la ley reitera innecesariamente un mismo criterio.

La salida favorable a una fórmula única tampoco satisface una lectura conforme al tenor literal del precepto y al uso común del lenguaje. En efecto, porque la primera expresión habla de "prevenir delitos", y la segunda dice "reducir los riesgos de comisión". Así, de los significados posibles de "prevenir", el más ajustado y común en este contexto equivale a evitar un

27 GONZÁLEZ CUSSAC, J. L.: Responsabilidad penal de las personas jurídicas (arts. 31 bis, ter, quáter y quinquies) en GONZÁLEZ CUSSAC, J. L. (dir.); GÓRRIZ ROYO, E. y MATALLÍN EVANGELIO, A. (coords.): Comentarios a la reforma del Código Penal de 2015, Valencia (Tirant lo Blanch), $2^{\mathrm{a}}$ ed., 2015, pags. 182 a 186. 
delito. Mientras que "reducir" apunta a una exigencia de menor grado, semejante a rebajar, decrecer o, sobre todo, disminuir un riesgo. Enunciado así, no puede decirse que evitar un delito posee el mismo significado que disminuir un riesgo.

Por todo ello, parece más saludable acoger el criterio de diversidad de fórmulas. $\mathrm{Y}$ en todo caso permite explorar si, de esta comprensión dispar, se pueden obtener réditos exegéticos siempre dentro del tenor literal posible del precepto y respetando el principio de vigencia en la interpretación.

De acuerdo pues con la tesis de la diversidad de fórmulas, la primera condición de idoneidad material estaría referida a la exigencia de "prevenir delitos de la misma naturaleza" que el cometido por la persona física representante, administrador o directivo._Su comprobación requiere que el juez penal verifique que, ex ante, el modelo de cumplimiento adoptado contenía medidas idóneas para prevenir (evitar) delitos de la misma naturaleza que el realmente cometido. Es decir, ha de poder afirmarse que ex ante, conforme a la experiencia general, el modelo de gestión incluía todas las medidas exigibles lógicamente para que no se pudiera cometer esa clase de infracciones penales.

Pero afirmar entonces que un programa, en abstracto y con carácter previo, era idóneo para evitar esa clase de delitos idéntica al efectivamente realizado, cuando en el supuesto enjuiciado estamos justamente enjuiciando su comisión, no deja cuanto menos de resultar paradójico ${ }^{28}$. Desde luego la paradoja, al menos parcialmente, puede esquivarse si descartamos un imposible parámetro de idoneidad material absoluta. En conse-

28 Por este motivo ABEL SOUTO califica esta regulación de "antinómica", puesto que el delito posterior demostrará la ineficacia del modelo preventivo, su inadecuación para prevenir el delito enjuiciado, es decir su falta de idoneidad. ABEL SOUTO, M.: Antinomias de la reforma penal de 2015 sobre programas de prevención que eximen o atenúan la responsabilidad criminal de la persona jurídica, en Corrupción y prevención de delitos de corrupción (A. Matallín Evangelio Dir.), Valencia (Tirant lo Blanch) 2018, p. 19. 
cuencia, por pura lógica, el parámetro de medición debe reducirse a una idoneidad material relativa ex ante ${ }^{29}$.

El criterio de idoneidad material relativa apunta a un parámetro de experiencia: así, conforme a criterios generales, un espectador objetivo diría ex ante que, con todos los conocimientos sociales disponibles, las medidas adoptadas resultaban idóneas para evitar la comisión de esta clase de delitos. Igualmente pueden resultar útiles los diferentes mecanismos que ofrece la teoría de la imputación objetiva, ya sea mediante el recurso a la adecuación (espectador objetivo), al fin de protección de la norma, o al de incremento de riesgo.

Podría decirse que el juez debe valorar si el programa de cumplimiento contiene medidas generalmente idóneas, es decir, suficientes para evitar la comisión de delitos de la misma naturaleza al cometido, conforme a la experiencia general. Aquí debe entenderse por experiencia general el conjunto de antecedentes existentes, tanto de carácter amplio como los referidos al sector, actividad, estructura, tamaño y precedentes de la sociedad enjuiciada. Por ejemplo, si esas medidas han sido hasta ahora adecuadas para evitar esta clase de delitos en empresas similares, si existen precedentes judiciales, si ha habido cambios normativos, etc. Y desde luego el historial de la propia sociedad encausada podrá ser relevante. En un sentido favorable a su estimación jugará si hasta el momento esas medidas han evitado incidentes de esa naturaleza y puede acreditarse. $\mathrm{Y}$ en sentido contrario a su estimación si las medidas ya se han mostrado insuficientes con anterioridad.

En síntesis, este criterio comporta que el juez dictamine que las medidas adoptadas eran idóneas, ex ante y conforme a la experiencia general, para evitar la comisión del delito enjui-

29 La distinción entre un parámetro de idoneidad absoluta y de idoneidad relativa se ha utilizado en la doctrina y jurisprudencia española desde hace más de un siglo, especialmente en materia de delito imposible, tentativa inidónea y tentativa irreal o supersticiosa. 
ciado, de modo que pueda decirse que este evento resultaba impredecible ${ }^{30}$.

También pueden desempeñar un papel en el juicio de idoneidad material relativa las hipótesis de causalidad estadística o procesos anómalos o inusuales de nexo causal, generalmente aceptadas como suficientes para atribuir un resultado. Con otras palabras, si la experiencia cuantitativa muestra que la adopción de esas medidas no siempre evita la comisión de esta clase de infracciones.

Igualmente puede desempeñar réditos interpretativos en este campo, la discusión en la teoría jurídica del delito de la relevancia del comportamiento de la víctima en situaciones que son calificadas como de autopuesta en peligro o de exposición voluntaria a un peligro que proviene de la acción de otro. En estos supuestos podría rechazarse la estimación como eximente o atenuante del programa de cumplimiento, a causa de la insuficiencia previsora de la víctima persona jurídica en relación a la conducta delictiva de la persona física.

La ideología del "accidente" o de la "fatalidad", esto es, la alegación de que los eventos suceden porque tienen que pasar, no me parece un camino convincente.

La segunda condición de idoneidad material también se halla formulado con una ambigüedad notable, pues compele al juez penal desarrollar un examen sobre la probabilidad de las medidas previstas en el programa para haber reducido "de forma significativa" el riesgo de su comisión. Esta segunda alternativa obliga al juez a efectuar una operación compleja sustentada en un juicio ex ante, contrafáctico y de valoración o cálculo de probabilidades.

30 En palabras de GÓMEZ-JARA DÍEZ, un programa será idóneo si reduce el riesgo de comisión de hechos delictivos a la categoría de "riesgo residual", es decir, de mantenerlo en unos niveles tolerables o permitidos. GÓMEZ-JARA DÍEZ, C.: El injusto típico de la persona jurídica (tipicidad", en BAJO FERNÁNDEZ, M.; FEIJÓO SÁNCHEZ, B. y GÓMEZ-JARA DÍEZ, C.: Tratado de responsabilidad penal de las personas jurídicas, Pamplona (Cizur Menor, Thomson Reuters-Aranzadi), 2016 pag. 132. 
En este caso el texto aparentemente parece demandar del juez penal un cálculo meramente cuantitativo, o si se prefiere estadístico, de reducción del riesgo de comisión a través de las medidas adoptadas en el programa de cumplimiento. ¿Cómo se mide la cantidad de reducción del riesgo necesario para exonerar la responsabilidad penal de la sociedad? ¿Basta solo con una pequeña cantidad de disminución?. No parece que esta conclusión pueda extraerse del texto. Porque el parámetro legal requiere que se acredite que las medidas adoptadas reduzcan el riesgo "de forma significativa". Y aunque el texto legal no ofrece una guía cuantitativa si remite a un criterio de esta naturaleza.

Por consiguiente, el juez penal, para poder aplicar esta segunda fórmula de idoneidad material relativa, tendrá necesariamente que examinar detalladamente el programa de cumplimiento. Pero la aplicación de este criterio requiere realizar varias operaciones consecutivas.

Primera, comenzará comprobando el mapa de riesgos en el que se cuantifica la probabilidad de comisión del delito enjuiciado en relación a las actividades sociales y departamentos de la empresa. Después analizará el cálculo de reducción de esos riesgos una vez adoptadas las medidas. Si el programa está mínimamente bien confeccionado, esta primera operación debe concluir que las medidas siempre conllevan una reducción significativa del riesgo de comisión. Pero cualquier imprevisión al respecto descartará ya su apreciación como eximente. En todo caso, se trata de un comprobación básica referida exclusivamente a lo reflejado en el programa de cumplimiento. Esto es, a un cotejo de lo que está previsto en un documento, a una hipótesis, pero que no refleja la realidad, o si se prefiere, su eficacia material.

Así pues, superado el control de idoneidad material desde una perspectiva interna del propio programa de cumplimiento, de su hipótesis, el juez deberá completarla desde una perspectiva objetiva y externa. Para ello dispone de diferentes instrumentos. Por ejemplo, si esa previsión se corresponde con el historial de 
la propia empresa, que muestre un descenso del riesgo fruto de las medidas adoptadas. Pero también puede recurrir a estadísticas empíricas externas, donde se establezca la idoneidad de ese tipo de medidas para rebajar el riesgo de esa clase de delitos. Así mismo resulta muy útil contrastar si las medidas adoptadas se adaptan a las previsiones legales, contractuales, recomendaciones y certificaciones dictadas para esos concretos ámbitos de riesgo. En este sentido recordar que ya existen numerosos sectores económicos altamente regulados, al igual que también ocurre respecto a ciertas actividades (v. gr. seguridad e higiene trabajadores; protección de datos; blanqueo de capitales; corrupción; medio ambiente y urbanismo...).

Todo lo anterior, y especialmente la última referencia, remite a la cuestión de lo que algunos autores denominan "fuentes de la estandarización" ${ }^{\prime 31}$. Y en sentido amplio, apunta a los criterios de verificación de un programa de cumplimiento. Todo ello lo veremos más adelante.

En resumen, deberá acreditarse que el programa contempla medidas idóneas para evitar una cantidad importante de riesgos asociados a esa actividad. Es decir, que efectivamente ha logrado disminuir gran parte de los riesgos delictivos detectados, aunque no todos. Entonces podrá afirmarse que la comisión del delito enjuiciado comporta un riesgo esporádico, ocasional y hasta excepcional. Que representa un bajo porcentaje de peligro merced a la eficacia reductora de las medidas adoptadas. Por ejemplo, que la corrupción entre particulares en la empresa es generalmente evitada, pero en este caso un directivo aceptó una comisión; o que habitualmente los controles estipulados en el programa impiden que los comerciales acepten dinero en efectivo, sin embargo, en algunas ocasiones lo admiten, ocasionando un riesgo de delito de blanqueo.

31 NIETO MARTÍN, A. en NIETO MARTÍN; LASCURAÍN SÁNCHEZ; BLANCO CORDERO; PÉREZ FERNÁNDEZ; GARCÍA MORENO.: Manual de cumplimiento penal en la empresa, Valencia (Tirant lo Blanch), 2015, pag. 111. 
Expresamente advierte el precepto que, en caso de llegar a un proceso penal, a la corporación no le bastará con mostrar que tiene un programa implementado, sino que habrá que comprobarse que ha sido adoptado y ejecutado "con eficacia". Lo que obliga inequívocamente al juez a valorar esta exigencia legal, siendo insuficiente la mera exhibición o presentación de un programa de cumplimiento.

B) La idoneidad de las medidas solo respecto al delito cometido o respecto a la globalidad del programa de cumplimiento. NIETO MARTÍN ha expuesto con claridad las dos opciones hasta ahora planteadas. A su juicio ambas propuestas están conectadas con el entendimiento profesado sobre el modelo de responsabilidad penal de la persona jurídica ${ }^{32}$.

Así, para NIETO MARTÍN, quienes piensan que el art. 31 bis CP responde al modelo de culpabilidad de empresa (autorresponsabilidad), coherentemente defienden un criterio de enjuiciamiento global del programa, como expresión de una cultura de cumplimiento, y no solo evaluar las medidas adoptadas para la clase de delito enjuiciado. Para ello proponen una valoración compleja en tres fases. En la primera se analiza el injusto del delito corporativo, esto es, la existencia de un defecto de organización y su relación con el delito cometido. Para ello recurren a comparativas con la normalidad en el sector, a las exigencias legales y a otras fuentes de estandarización. En la segunda fase examinan si el delito puede considerarse expresión del riesgo consecuencia del defecto de organización. Y en la tercera, persiguen averiguar si la empresa posee una cultura de cumplimiento, para lo cual toman en consideración una serie de datos relativos al grado de compromiso de la sociedad con la implantación efectiva del programa de cumplimiento $^{33}$.

32 NIETO MARTÍN, A. en NIETO MARTÍN; LASCURAÍN SÁNCHEZ; BLANCO CORDERO; PÉREZ FERNÁNDEZ; GARCÍA MORENO.: Manual de cumplimiento penal en la empresa, Valencia (Tirant lo Blanch), 2015, pag. 80 .

33 NIETO MARTÍN, A.: Manual... cit. pags. 81-82. 
Por el contrario, quienes creen que el art. 31 bis CP contiene un modelo de heterorresponsabilidad, consideran decisivo el caso concreto. Esto es, que la eficacia mide exclusivamente las medidas adoptadas en relación al delito cometido. Desde esta perspectiva el objeto del proceso penal no es evaluar la eficacia general del programa ni los esfuerzos preventivos generales de la empresa. Para el citado autor esta es la tesis sustentada en la Circular 1/2016 de la Fiscalía General del Estado ${ }^{34}$.

Tras analizar las dos alternativas referidas y reconociendo su utilidad, NIETO MARTÍN expone sus críticas ${ }^{35}$ y formula una propia, a la que denomina "test del debido control". En su opinión la discusión teórica no es tan decisiva en esta cuestión, si se parte, advierte, de "cómo funciona un programa como herramienta del debido control o de prevención de delitos". Así pues, el núcleo de su propuesta descansa en la noción de "debido control", que sutilmente circunscribe a empresas medianas y grandes ${ }^{36}$.

Su propuesta, que admite que puede ser cuestionada, descansa en cuatro argumentos. Los dos primeros los extrae

34 La Circular de la Fiscalía General del Estado 1/2016, de 22 enero, considera que pone en entredicho la validez de un programa, por ejemplo, el examen de los siguientes factores: la gravedad de la conducta delictiva; su extensión en la corporación y el alto número de empleados implicados; la baja intensidad del fraude; la frecuencia y duración de la actividad criminal; la firmeza en la respuesta en anteriores ocasiones; el mantenimiento en el cargo de administradores, directivos o empleados que hayan sido sometidos a procedimientos penales; la existencia de anteriores procedimientos penales; la imposición de sanciones administrativas; la adopción de sanciones disciplinarias contra los infractores; la restitución o reparación inmediata del daño.

35 Critica expresamente la Circular 1/2016 de la Fiscalía General del Estado $1 / 2016$, de 22 enero, porque circunscribe la medición de la eficacia de las medidas no ya al tipo de delito que se ha cometido, sino al hecho concreto y a su autor. Y el debido control requiere una operación compleja y un análisis global. Por su parte, discrepa de la tesis propuesta por los defensores de la culpabilidad de empresa, aunque admite que es más acertada, porque trocean indebidamente la medición de la eficacia del programa. NIETO MARTÍN, A. .: Manual... cit. pag. 84.

36 NIETO MARTÍN, A. .: Manual ... cit. pag. 82. 
tanto de la "práctica empresarial", como de un sector del Derecho comparado, en concreto de aquellos países en los que el legislador ha indicado expresamente en qué consisten las medidas de prevención. Y ello porque en ambos ámbitos existe una "identificación entre prevención y programas de cumplimiento". El tercer argumento deriva del texto del actual art. 31 quater d) $\mathrm{CP}^{37}$, es decir, de la circunstancia atenuante consistente en "haber establecido, antes del comienzo del juicio oral, medidas eficaces para prevenir y descubrir los delitos que en el futuro pudieran cometerse con los medios o bajo la cobertura de la persona jurídica". Y el cuarto y último, porque el Código Penal, tras la reforma de 2015, ofrece también un modelo de programa de cumplimiento acorde, en lo esencial, con la estructura, elementos y criterios internacionales.

Expuestos sus argumentos y tras enumerar los elementos esenciales de un programa de cumplimiento, afirma que "estos elementos forman un todo, por lo que su eficacia no puede determinarse por separado, ni tenerse en cuenta para apreciar que es el debido control sólo una de las partes del programa". A lo que añade que "esta visión global del debido control es coherente con la visión del control interno, tal como se entiende a partir del informe COSO"38.

A partir de aquí formula su sugerente propuesta del "test de debido control". Lo estructura en cuatro operaciones para medir la eficacia preventiva de un programa de cumplimiento.

En la primera, "previsibilidad del delito", se centra en el "análisis de riesgos" desarrollado en el programa de cumplimiento, instrumento que califica con razón de esencial. Una segunda fase consiste en examinar la "eficacia de los controles ex ante", que a su vez subdivide en dos: "la eficacia de los ele-

37 Hay que subrayar que la propuesta de NIETO MARTÍN está formulada durante la vigencia del texto de 2010 , en la que esta atenuante, con idéntica redacción, se contenía en el art. 31 bis d); si bien, el autor ya hace referencias al Proyecto de reforma de 2015 con su redacción actual.

38 NIETO MARTÍN, A. .: Manual ... cit. pag. 83. 
mentos básicos o trasversales", que lo asimila a la noción de "entorno de control"; y la "eficacia de los controles específicos", vinculada a las regulaciones legales, estándares y certificación existentes. Una tercera operación, "eficacia de los controles ex post", examina la relación entre los controles aplicados y el hecho realizado. El cuarto y último paso lo denomina "exigibilidad del debido control", comportando la aplicación de este principio general a esta materia ${ }^{39}$.

Sin restar mérito ni originalidad a las propuestas examinadas, en particular a la ofrecida por NIETO MARTÍN, mi punto de vista sigue aferrado al texto legal. Además, tampoco es exacta la clasificación entre un binomio autorresponsabilidad/ hecho global y heterorresponsabilidad/hecho concreto. Así, por citar solo algún ejemplo, GALÁN MUÑOZ, que indudablemente propugna un modelo de autorresponsabilidad, atribuye al hecho delictivo concreto una función central, en la que se vincula causalmente con la omisión de las medidas de vigilancia que estaban obligados a aplicar ${ }^{40}$. Lo mismo sucede con GOMÉZJARA DÍEZ, quien afirma que el art. 31 bis CP "exige que las medidas de vigilancia y control estén referidas en concreto al delito cometido" ${ }^{\text {. }}$.

En efecto, el texto legal vigente inequívocamente dice "delitos de la misma naturaleza". De suerte que las medidas contenidas en el programa deben ser idóneas para prevenir "delitos de la misma naturaleza". o para reducir de forma significativa el riesgo de "su" comisión. De modo que, el art. 31 bis 2, $1^{\circ} \mathrm{CP}$ establece como criterio de evaluación de la idoneidad de las medidas para desplegar su eficacia eximente o atenuante, la referencia a los delitos de la "misma naturaleza" que el enjuiciado. Eso es lo que la ley exige que coteje el juez penal. El resto de

39 NIETO MARTÍN, A. cit. pags. 84 a 89.

40 GALÁN MUÑOZ, A.: Fundamentos y límites de la responsabilidad penal de las personas jurídicas..., cit. pags. 130-131, y 165 y ss.

41 GÓMEZ-JARA DÍEZ, C.: El injusto típico de la persona jurídica (tipicidad), cit. pag. 123. 
medidas previstas y ejecutadas en el programa de cumplimiento no son objeto de evaluación en esta operación. No se trata de un juicio general al grado de cumplimiento y previsión de la sociedad, sino acotada al objeto de un proceso penal determinado ${ }^{42}$.

Este es el criterio legal para que el programa de cumplimiento surta eficacia eximente o atenuante desde la reforma de 2015. La denominada "práctica empresarial", noción por otra parte bastante difusa, no puede en absoluto sobreponerse al tenor literal de la norma. Tampoco es determinante en la interpretación del derecho vigente español el recurso a una siempre compleja comparativa con el derecho extranjero. Además, el propio NIETO MARTÍN la limita a un sector del derecho comparado, en concreto, al de aquellos países en los que el legislador ha indicado expresamente en qué consisten las medidas de prevención. El mismo criterio de selección es ya discutible. Pero más inseguro todavía será acordar la aplicación de esta selección de ordenamientos "afines". En todo caso, se podría objetar que algunos de los países cuyas normas describen las medidas de prevención consideradas idóneas, no otorgan eficacia eximente al programa de cumplimiento, y tan solo lo consideran a efectos de la determinación de la penalidad.

El argumento a favor del examen global frente al concreto sustentado en una "identificación entre prevención y programas de cumplimiento" no me parece consistente. No lo es porque no se discute esta identificación, sino justamente los términos de evaluación de la idoneidad preventiva de un programa concreto.

Tampoco comparto que, como el Código Penal vigente desde 2015 contempla un modelo de programa de cumplimiento acorde, en lo esencial, con la estructura, elementos y criterios internacionales, de ello necesariamente se derive una evaluación global del programa de cumplimiento y no referida al delito concreto. Ello porque creo que NIETO MARTÍN se está refiriendo a

42 En sentido similar al aquí sostenido GALÁN MUÑOZ, A.: Fundamentos y límites de la responsabilidad penal de las personas jurídicas..., cit. pag. 139. 
los "requisitos" de los programas de cumplimiento, regulados en el art. 31 bis 5 CP. Este apartado legal contiene una regulación general o global de la estructura y elementos de cualquier programa de cumplimiento, si bien es cierto que estos "requisitos" están explícitamente referidos al cumplimiento de la condición examinada de idoneidad. Pero aquí no estamos comprobando que un programa se estructura conforme a la ley, sino si un concreto programa de cumplimiento lo consideramos idóneo, en un proceso penal concreto, para eximir o atenuar la responsabilidad de la sociedad por el delito que es acusada en concreto.

No obstante, la propuesta sugerida por NIETO MARTÍN es transcendente, aunque en mi opinión hay que afrontarla conforme lo expuesto por LEÓN ALAPONT. Para este autor, deben distinguirse dos planos: "1) el de la idoneidad de las concretas medidas que se establezcan para la prevención de cada una de las conductas delictivas en las que se pueda incurrir, lo cual sólo podrá ser objeto de valoración por el juez o tribunal de forma casuística e individualizada; $y, 2)$ el del contenido o medidas en abstracto que se contemplen con carácter general para la prevención y descubrimiento de cualquiera de los delitos atribuibles a una persona jurídica". Así, respecto del primer plano, un parámetro básico para valorar su idoneidad será que éstas resulten proporcionadas al riesgo en cuestión y a la actividad de que se trate. En cuanto al segundo plano, no podrá calificarse de idóneo un programa de cumplimiento que no contemple todas y cada una de las exigencias previstas en el art. 31 bis $5 \mathrm{CP}^{43}$.

Por consiguiente, en este momento no valoramos ni una idoneidad indeterminada ni la estructura de todo el programa. Lo que la ley exige es medir la idoneidad concreta de las medidas adoptadas en relación al delito enjuiciado. Aunque ciertamente la valoración de la condición de idoneidad requiere, por así decirlo, de dos fases de análisis: el primero, examinando la

43 LEÓN ALAPONT, J.: "Criminal Compliance: análisis de los arts. 31 bis 2 a 5 CP y 31 quater CP", Revista General de Derecho Penal, $\mathrm{n}^{\circ}$ 31, mayo 2019, pag. 11. 
idoneidad temporal, formal y material de las medidas adoptadas en relación estricta al delito de referencia; y, segundo, comprobar que el programa contiene los elementos requeridos (requisitos conforme al art. 31 bis $5 \mathrm{CP}$ ). Lo que en este momento nos pide la ley es enjuiciar si la empresa adoptó medidas idóneas para prevenir o evitar esta clase de delitos. En el modelo español se regulan de modo diferente el juico de idoneidad sobre las medidas preventivas para eximir o atenuar, y el examen de los requisitos del programa (estructura y elementos del programa).

En realidad, el art. 31 bis 5 describe los elementos estructurales mínimos que ha de revestir un programa para ser jurídico-penalmente valorado como idóneo. Pero que una sociedad posea un programa estructurado con todos estos requisitos legales no es suficiente para cumplir la condición de idoneidad. Son "requisitos" necesarios, pero no suficientes para obtener la exención o atenuación de la responsabilidad penal, pero siempre referida en el texto legal a delitos y riesgos de la misma naturaleza al enjuiciado.

Por otra parte, la atenuante del art. 31 quater d) no puede usarse para modificar el sentido literal del art. 31 bis $2,1^{\circ}$ generando una reinterpretación de este último. Ambos preceptos poseen diferentes ámbitos de aplicación. El art. 31 quater d) está proyectado a una actuación ex post del delito cometido y sin una exigencia expresa de correlación entre las medidas adoptadas y "los delitos que en el futuro pudieran cometerse". De modo diverso, el primero de los preceptos lo hace midiendo ex ante la idoneidad del programa de cumplimiento en relación al concreto delito enjuiciado.

Es importante no olvidar que el modelo español es muy generoso al contemplar la posibilidad que un programa de cumplimiento opere como eximente ${ }^{44}$. Una ampliación mayor de

44 Una visión crítica con el modelo de compliance introducido en el Derecho penal español, BUSATO, P. C.: "Lo que no se dice sobre criminal compliance", Revista Electrónica de Estudios Penales y de la Seguridad, 1, 2017; del mismo: Tres tesis..., cit, pags. 109 y ss. 
este espacio vía interpretaciones materiales y forzando el texto de la ley no puede compartirse. Como tampoco el fundamento y consecuencias de esta ampliación. Porque un proceso penal no es una auditoría, ni externa ni menos interna de la propia empresa. Ni tampoco es un órgano de evaluación de la calidad.

En consecuencia, ampliar más aún de lo que ya hace la norma la virtualidad eximente del programa de cumplimiento, pretendiendo una evaluación global de su idoneidad, comporta transformar el proceso penal en un juico general a la empresa. Pero solo tomando en consideración lo que le beneficia. Es tanto como decir que, aunque esté siendo juzgado por defraudación fiscal y las medidas adoptadas sean insuficientes, en lo demás, o en una parte del resto del programa, se aprecia hipotéticamente que es idóneo para evitar la comisión de otros delitos. Pero no estamos enjuiciando "lo demás", sino solo la responsabilidad derivada de la comisión de un delito concreto. Y eso es lo que medimos, siempre limitado al objeto del proceso penal.

Ahora bien, contemplado en su conjunto el sistema legal español, en lo referente al régimen de eximentes y atenuantes, podría decirse que aparentemente se aprecia un espacio vacío. Así, entre el ámbito de la eximente o atenuante del art. 31 bis 2, $1^{\mathrm{o}} \mathrm{y}$ el de la atenuante ex post del art. 31 quater d), se abre un espacio sin aparente respuesta legal precisa. Este espacio estaría ocupado por los supuestos en que no se acredita la idoneidad de las medidas para prevenir o reducir el delito cometido. Pero sin embargo, la sociedad alega que el resto de su programa si funciona adecuadamente como instrumento preventivo. En estos casos obviamente ya no existe parámetro concreto, pues la comparación no se refiere a un delito concreto, sino a la idoneidad global y siempre hipotética del programa de cumplimiento en su conjunto.

Junto a la dificultad práctica intrínseca a esta operación, se suma la falta de apoyo legal para activarla. Por ello no considero viable construir una eximente supralegal, ni tampoco una atenuante analógica sin habilitación legal expresa. Si podría va- 
lorarse por el juez para la elección de la clase de pena en el marco de discrecionalidad existente y también para la modulación de la misma (individualización judicial en sentido estricto).

C) Criterios de verificación y "fuentes de estandarización". Ya se ha subrayado la dificultad de comprobar la condición de idoneidad material. No hay un método que ofrezca una certeza absoluta. Tampoco un marco normativo exacto cuyo seguimiento estricto garantice un juicio positivo de idoneidad. Es imposible afirmar ex ante que aplicando una serie de medidas se evitará la comisión de delitos o se reducirá el riesgo de comisión. Todo lo que tenemos son referencias normativas, la experiencia de la praxis y por tanto el juego de probabilidades. De ahí que la empresa, por esta falta de parámetro de validación, nunca pueda estar completamente segura de que se hayan adoptado eficazmente las estrategias para la reducción del riesgo de comisión de los delitos seleccionados.

La cuestión podría formularse de este modo: ¿Quién, cómo, conforme a qué criterios, parámetros o normas se decide sobre la idoneidad o eficacia de un programa de cumplimiento?.

En realidad, esta es la mayor dificultad de los modelos de responsabilidad criminal de la persona jurídica, que como el nuestro desde 2015, otorgan alguna relevancia jurídica a los programas de cumplimiento. Por tanto, en aras a la seguridad jurídica debe ahondarse en la determinación de los criterios objeto de evaluación de la eficacia preventiva de un programa de cumplimiento. Pero este propósito no resulta en absoluto sencillo.

Desde luego debe profundizarse más allá de obviedades y generalidades del estilo que los programas deben ser claros, precisos, por escrito, adaptados a cada empresa y a sus riesgos, evitando la mala práctica del "copia y pega", obedientes con la legalidad y a ser posible vinculados a códigos de conducta éticos.

NIETO MARTÍN inscribe este problema en lo que denomina "proceso de estandarización", una suerte de lex artis de los 
contenidos y metodología del programa de cumplimiento. En su opinión, se ha alcanzado un acuerdo generalizado sobre los componentes o elementos en que se ha de estructurar un programa de cumplimiento. Pero no ocurre lo mismo en lo referente a lo que llama los "criterios de calidad del sistema o de cada uno de sus elementos". El reto reside en concretar la idea de "debido control" en un programa de cumplimiento de una organización empresarial. En todo caso advierte que asistimos a una evolución similar a la desarrollada en las últimas décadas en el delito imprudente, y en las categorías de riesgo permitido y deber de cuidado. Este proceso de normativización es fruto de la regulación administrativa de numerosos sectores, de la estandarización privada y de la formalización mediante protocolos de la lex artis profesional. Y a su juicio, el juez penal no puede desconocer estos patrones normativos en el marco del art. 31 bis $\mathrm{CP}^{45}$.

En resumen, las fuentes de este proceso de estandarización podrían agruparse en: legislativas en sentido estricto; recomendaciones y directrices de organismos públicos y privados, incluidos los códigos de buen gobierno corporativo, y; las certificaciones.

Nada que objetar a este planteamiento y a la utilidad de acudir a estos instrumentos para valorar la idoneidad o eficacia de las medidas preventivas contenidas en un programa de cumplimiento. Pero si es necesario recordar que el grado de sujeción del juez penal a cada una de estas fuentes es muy diferente. Porque mientras la sujeción a las fuentes legales es absoluta, a las otras deviene más débil, en especial las referidas a directrices de organizaciones privadas y a las certificaciones. Esto no quiere decir que no las deba tomar en consideración, pero en ningún caso está sujeto a ellas.

Por esta razón, que nace de las fuentes constitucionales del Derecho penal, las certificaciones externas en modo alguno pueden ser consideradas como una fuente primaria y vinculante.

45 NIETO MARTÍN, A. .: Manual... cit. pags.111 a 115. 
De aquí que no puedan concebirse como un escudo, una garantía o un crédito absoluto de la eficacia del programa. Tan solo constituyen un elemento adicional más de la valoración que corresponde en exclusiva al juez penal.

$\mathrm{Al}$ anterior argumento de carácter formal-constitucional, hay que añadir un déficit material-constitucional de taxatividad. Ello es debido al alto grado de indeterminación con el que están redactadas, lo que dificulta extraordinariamente su utilidad en el proceso penal ${ }^{46}$. Por esta razón no acabo de compartir la viabilidad de una prueba pericial con el objetivo de valorar su eficacia, aunque se trasmuten los términos legales y en su lugar se hable de "validar su suficiencia" 4 .

Téngase en cuenta que la función de las certificaciones si es validar la calidad de un programa, pero este parámetro no se corresponde exactamente con la valoración de la idoneidad o eficacia eximente de las medidas para evitar infracciones o disminuir el riesgo delictivo.

3.2. Órgano con poderes autónomos de supervisión del funcionamiento y cumplimiento del programa.

La segunda condición precisa que "la supervisión del funcionamiento y del cumplimiento del modelo de prevención implantado ha sido confiada a un órgano de la persona jurídica con poderes autónomos de iniciativa y control o que tenga encomendada legalmente la función de supervisar la eficacia de los controles internos de la persona jurídica".

Adviértase que esta condición no se refiere al órgano que ha de aprobar el programa de cumplimiento, sino al que ha de

46 Podrían citarse otras, pero aquí basta con remitir a una lectura de la ISOUNE 19600, de sistemas de gestión de programa de cumplimiento, para advertir un elevado grado de indeterminación en su formulación.

47 En sentido contrario se manifiesta MAGRO SERVET, V.: "Viabilidad de la pericial de programa de cumplimiento para validar la suficiencia del programa de cumplimiento normativo por las personas jurídicas", Diario La Ley, $n^{\circ}$ 9337, de 15 enero 2019. 
"supervisar su funcionamiento y cumplimiento". Lo decisivo para cumplimentar esta condición es comprobar que la sociedad posee un órgano con poderes autónomos de iniciativa y control sobre el funcionamiento y cumplimiento del programa. Esta comprobación reviste dos operaciones, una formal y otra material. La primera, destinada a constatar que efectivamente los órganos sociales han aprobado conforme a las exigencias legales, un órgano de estas características y formalmente le han atribuido las citadas funciones. La segunda comprobación se dirige a examinar si en la realidad este órgano posee y ejerce efectivamente estas funciones.

El texto no fija explícitamente las funciones a desarrollar por este órgano. Deben estar orientadas a vigilar y controlar que el programa de cumplimiento aprobado es efectivo. Para ello es fundamental, cuanto menos: contar con personal con conocimientos y experiencia; disponer de medios técnicos adecuados; recursos financieros suficientes; tener acceso a procesos internos; capacidad de formación y comunicación a todos los empleados y directivos; un "canal de denuncia" de incidentes; y desde luego, independencia del consejo de administración, contando con mecanismos para la gestión de los conflictos de intereses ${ }^{48}$. En realidad las funciones esenciales de este órgano se desprenden de los requisitos de los programas, en particular de las contenidas en los numerales $3^{\circ}$ y $4^{\circ}$ del propio art. 31 bis $5 \mathrm{CP}$. Los otros cuatro requisitos de este precepto no necesariamente tienen que estar atribuidas al órgano de supervisión, sino que se exigen al programa, pudiendo desempeñarse por otros órganos sociales.

Como desarrolla LEÓN ALAPONT, lo esencial es que este órgano de vigilancia ostente poderes autónomos de iniciativa y de control. Por ejemplo, "entre los primeros la facultad para iniciar una investigación interna; para suspender tempo-

48 Subraya la importancia de la capacidad de este órgano para resolver posibles conflictos de intereses la Circular 1/2016 de la Fiscalía General del Estado, de 22 enero, pag. 47. 
ralmente o paralizar una determinada operación; para tener acceso a cualquier tipo de información o la potestad para dar órdenes e instrucciones, entre otros. Respecto de los segundos, podríamos citar la supervisión de determinadas actividades, la capacidad de fiscalización, recabar informes, etc". En resumen, advierte el citado autor, que el órgano de vigilancia posea la autoridad necesaria para llevar a cabo cualquier tipo de actuación que contribuyera al funcionamiento y cumplimiento del programa de cumplimiento $^{49}$. De ahí que, como advierte DE LA MATA BARRANCO, los poderes autónomos de vigilancia y control deben hacerse extensivos al conjunto de personas físicas que pueden cometer un delito que origine la responsabilidad penal de la sociedad, con lo que esta referencia es más amplia y no se limita a las descritas en el art. 31 bis $1 \mathrm{~b}$ ) $\mathrm{CP}^{50}$.

Para el ejercicio de estas funciones la persona jurídica tiene tres alternativas orgánicas:

a) Creación y atribución a un órgano específico con poderes autónomos para la supervisión del funcionamiento y cumplimiento del modelo de prevención. Es decir, estas funciones se encargan a un órgano específico con poderes autónomos de control creado ad hoc por la propia persona jurídica (responsable de cumplimiento).

b) No es necesario crear un órgano específico si éste ya está previsto para verificar los controles internos de riesgos. Lo único imprescindible es adoptar una decisión formal por el que a este órgano se le atribuyan estas nuevas funciones de supervisión y cumplimiento del programa de cumplimiento.

49 LEÓN ALAPONT, J.: "Criminal Compliance: análisis de los arts. 31 bis 2 a 5 CP y 31 quater CP", Revista General de Derecho Penal, $n^{\circ} 31$, mayo 2019, pag. 19.

50 DE LA MATA BARRANCO, N. J.: El órganos de cumplimiento en la exención de responsabilidad penal de las personas jurídicas: indefiniciones y precisiones, en Corrupción y prevención de delitos de corrupción (A. Matallín Evangelio Dir.), Valencia (Tirant lo Blanch) 2018, pags. 461. 
c) El precepto contiene una segunda alternativa para sociedades sometidas a una supervisión legalmente establecida. Por ejemplo para sociedades cotizadas. En estos supuestos, de nuevo bastará con un acuerdo social para atribuir estas funciones al órgano ya existente y que por imperativo legal posea facultades de control interno.

Naturalmente no todas las funciones relacionadas con el programa de cumplimiento han de estar atribuidas a este órgano, pudiendo haber otros órganos con facultades en la materia. Lo que exige inequívocamente el precepto es que posea formal y materialmente las de supervisión del funcionamiento y del cumplimiento del modelo.

Este órgano puede ser unipersonal o colegiado, pero en todo caso debe formar parte de la persona jurídica, lo que excluye una externalización elevada de sus funciones. Nada impide que el órgano de vigilancia se organice con otras unidades dependientes o subordinadas, ni que una parte se complemente con servicios externos ${ }^{51}$.

Por último advertir que, si este órgano o la persona física encargada, comete un delito, generalmente por omisión, dará lugar a una responsabilidad penal de la persona jurídica conforme al art. 31 bis 1 a) CP, esto es, integra el nivel de representantes, administradores y directivos. Esta consecuencia enlaza directamente con la condición contenida en el art. 31 bis $2,4^{\text {a }} \mathrm{CP}$.

\subsection{Que el delito se haya cometido eludiendo fraudu- lentamente los modelos de prevención}

La tercera condición se contiene en el art. 31 bis $2,3^{\mathrm{a}} \mathrm{y}$ dice: "los autores individuales han cometido el delito eludiendo fraudulentamente los modelos de organización y prevención". La clave reside en la expresión "eludiendo fraudulentamente".

51 DE LA MATA BARRANCO, N. J.: El órganos de cumplimiento en la exención de responsabilidad penal de las personas juridicas: indefiniciones y precisiones, en Corrupción y prevención de delitos de corrupción (A. Matallín Evangelio Dir.), Valencia (Tirant lo Blanch) 2018, pags. 465 y 466. 
De modo que, para que la exención se aplique, requiere que el autor individual (persona física), haya cometido el delito "eludiendo fraudulentamente" los modelos de prevención. Se trata de una condición añadida a las anteriores y de igual forma necesaria para que el programa despliegue eficacia eximente o atenuante.

Así pues, para ser 'efectivo', el programa de prevención tiene que haber sido adoptado y ejecutado previamente a la comisión del delito por el órgano de administración, e idóneo temporal, formal y materialmente para prevenir delitos de la misma naturaleza o para reducir de forma significativa el riesgo de su comisión (condición primera), y, confiado a un órgano específico o ejercido por quien legalmente corresponda (condición tercera). Y a pesar de todo ello, un representante legal, o persona con poder de decisión o control, ha conseguido quebrar todo ese conjunto de medidas preventivas precisamente diseñadas para impedir o dificultar la comisión de ilícitos penales. Justamente por esto mismo no se podría decir que el programa de cumplimiento es "eficaz", al menos a efectos penales. De ahí que la burla por el representante, administrador o directivo de las medidas preventivas deba ser "fraudulenta". No basta pues con cualquier mecanismo de elusión, sino que ha de revestir una entidad suficiente y ésta se cifra en el uso de un medio fraudulento. Esta exigencia implica de entrada una intención de esquivarlas. La simple elusión sin un engaño revelaría la ineficacia o insuficiencia del modelo preventivo, o su formulación con una suerte de agujeros destinados a una flexibilidad en el cumplimiento normativo expresiva de un control inadecuado, permisivo o cómplice.

El fraude excluye los supuestos donde hay facilidad de elusión, pues eso muestra la debilidad del programa ${ }^{52}$.

52 En este sentido se expresa la doctrina mayoritaria, por todos y con la bibliografía allí citada, LEÓN ALAPONT, J.: “Criminal Compliance: análisis ....” cit. pag. 20. Igualmente lo afirma la Circular de la Fiscalía General del Estado 1/2016, de 22 de enero, pag. 42. 
La noción de fraude posee una considerable tradición en nuestra cultura jurídica, pero no por ello será fácil acordar las actuaciones que merezcan este calificativo. Ciertamente, fraude implica siempre engaño. Pero también es sabido que dentro de la "gran familia de los fraudes" precisamente las diferencias se construyen por los distintos tipos de engaño relevantes. Pues bien, la ausencia en el texto legal de mayores precisiones, invita a considerar válido cualquier clase de engaño, y por ende, de fraude. Por tanto será válido el engaño antecedente, coetáneo y posterior, o el llamado omisivo ${ }^{53}$.

En este sentido QUINTERO OLIVARES señala que la elusión fraudulenta significa que, pese a la perfección de los modelos de control, los autores del hecho los burlaron con astucia o cualquier otra artimaña que ocultara sus actuaciones ${ }^{54}$.

Por pura lógica y también por derivación de lo dispuesto expresamente en la condición primera, el comportamiento fraudulento del directivo está referido a la elusión de las medidas específicamente adoptadas para evitar el delito enjuiciado.

\subsection{Omisión o ejercicio insuficiente de las funciones de supervisión, control y vigilancia}

En el art. 31 bis $2,4^{\text {a }}$ se regula la cuarta y última condición para estimar eficaz un programa de cumplimiento si el delito de referencia ha sido cometido por un representante, administrador o directivo. Dice así: "no se ha producido una omisión o ejercicio insuficiente de sus funciones de supervisión, vigilancia y control por parte del órgano al que se refiere la condición $2^{a, .}$.

53 GONZÁLEZ CUSSAC, J. L.: Responsabilidad penal de las personas jurídicas (arts. 31 bis, ter, quater y quinquies) en GONZÁLEZ CUSSAC, J. L. (dir.); GÓRRIZ ROYO, E. y MATALLÍN EVANGELIO, A. (coords.): Comentarios a la reforma del Código Penal de 2015, Valencia (Tirant lo Blanch), 2a ed., 2015, pag. 187.

54 QUINTERO OLIVARES, G.: Art. 31 bis; art. 31 ter; art. 31 quater; $y$, art. 31 quinquies, en QUINTERO OLIVARES, G. (Dir.): Comentarios al Código Penal español. Tomo I, Pamplona (Cizur Menor, Thomson ReutersAranzadi), 2016, p. 397. 
Con la cuarta condición se pretende cerrar el círculo de lo que la ley entiende como eficaz. El distintivo de un programa efectivo es que el modelo de organización y control haya permitido ejercer la "diligencia debida" o "debido control" para intentar identificar y prevenir conductas criminales llevadas a cabo por sus máximos responsables. Y no se actúa como es debido y exigible jurídicamente, cuando se omiten actos relevantes de supervisión, vigilancia y control, ni cuando se ejercen de forma insuficiente ${ }^{55}$.

En ambos casos se trata de evaluaciones de estricta naturaleza normativa. Es decir, no basta con que el órgano de administración haya adoptado y ejecutado un programa de cumplimiento adecuado e idóneo; ni que haya atribuido a un órgano especializado y facultado para su supervisión; ni que el directivo haya cometido el delito eludiendo mediante fraude el programa. Además de todo ello, ha de comprobarse que el órgano encargado de su funcionamiento y cumplimiento ha actuado, en relación al delito enjuiciado, con la diligencia de control y supervisión exigidas en las leyes y reflejada en el programa de cumplimiento.

Esta condición se dirige expresamente al órgano encargado de supervisar el funcionamiento y cumplimiento del programa. Es decir, el que tenga atribuidas formalmente esas funciones. El examen de las funciones de vigilancia y supervisión naturalmente se acota al cumplimiento de las medidas relacionadas con el delito cometido. No se trata de una evaluación del grado de funcionamiento general del órgano de supervisión, sino de su ejercicio respecto de la infracción enjuiciada.

Aunque el precepto no especifique las funciones omitidas o ejercidas insuficientemente, es claro que se refiere a las

55 En realidad, como ya propuse, la misma introducción de los programas de cumplimiento, en particular los cuatro últimos apartados del art. 31 bis CP, constituyen una fuente esencial para concretar los deberes que a cada sujeto le corresponde cumplir. En GONZÁLEZ CUSSAC, J. L.: Responsabilidad penal de las personas jurídicas (arts. 31 bis, ter, quater y quinquies), cit., pags. $171 \mathrm{y}$ ss. 
contenidas y ya analizadas en la condición segunda, esto es, la supervisión, vigilancia y control ${ }^{56}$. Más concretamente podría decirse que se concretan en dos esenciales: recibir y gestionar las denuncias recibidas o detectadas, y, transmitirlas al órgano de administración. Como quiera que el ejercicio de facultades disciplinarias no siempre estará atribuido a este órgano, sino que lo ostentará el consejo de administración, habrá que estar a lo dispuesto en cada caso en el reparto de la función de imposición de sanciones ${ }^{57}$.

Esta condición se puede incumplir de dos formas: mediante una omisión o con un ejercicio insuficiente. La primera se dará en los casos en que el órgano de vigilancia no ejerza la supervisión o el cumplimiento de las medidas preventivas adoptadas para evitar la comisión del delito enjuiciado o reducir el riesgo de comisión. Esto es, cuando no advierta el riesgo jurídicamente exigible, o cuando advertido no actúe para mitigarlo conforme lo debido. Naturalmente también se deben incluir los supuestos manifiestos de abandono o pasividad. La segunda forma de incumplir la condición está formulada con términos más abiertos, al referirse a un "ejercicio insuficiente". Es decir, el órgano de vigilancia ha advertido el riesgo pero no lo ha evaluado como debía, infravalorando su entidad. O bien, aunque haya catalogado correctamente el riesgo, no ha adoptado todas las medidas necesarias para evitar su materialización.

En este punto conviene observar la constante evolución de los parámetros normativos de enjuiciamiento. Así, se ha pasado de la exigencia de infracción de deberes concretos, a un examen de la infracción de un deber general de cuidado. Este

56 Así lo expresa LEÓN ALAPONT, J.: "Criminal Compliance: análisis de los arts. 31 bis 2 a 5 CP y 31 quater CP”, Revista General de Derecho Penal, $\mathrm{n}^{\circ}$ 31, mayo 2019, pag. 21.

57 AGUILERA GORDILlO, R.: “Compliance Penal en España. Régimen de responsabilidad penal de las personas jurídicas. Fundamentación analítica de base estratégica. Lógica predictiva y requisitos. Compliance Program Penal,", Pamplona (Cizur Menor, Thomson Reuters-Aranzadi), 2018, pags. 145 y ss. 
tránsito comporta la exigencia de vigilar que su actuación previa genere algún peligro, porque entonces luego le obligará a un actuar positivo diligente para evitar cursos causales lesivos. De esta forma, por ejemplo la imprudencia, ha ido abandonando la referencia de la relación entre infracción del deber de cuidado y resultado, y se ha trasladado hasta la medición del incremento de riesgo.

A su vez, se ha producido una expansión del criterio del "defecto cognitivo", por lo que se ha convertido en una especie de "norma modal" referida entonces al "cómo hay que actuar". Este desarrollo abandona el parámetro externo del hombre-medio, esto es, el examen del comportamiento debido conforme a pautas externas (reglas sociales). Progresivamente se ha ido sustituyendo por el uso de "normas cautelares" frente a "comportamientos defectuosos". En este salto se aprecia una seria dificultad, pues no es fácil determinar cuál es el comportamiento debido o el que se debía evitar.

En todo caso es indiscutible el protagonismo atribuido normativamente a este órgano y de ello se pueden derivar importantes consecuencias jurídico-penales ${ }^{58}$.

Para finalizar, quizás resulte útil observar que nos encontramos ante una condición con cierta semejanza a la estructura del "caso fortuito". El texto legal viene a exigir una actuación con la diligencia debida, conforme al debido control, a lo que se puede exigir jurídicamente. Si a pesar de todo ello, esto es, con la equivalencia en el caso fortuito de haber obrado sin dolo ni imprudencia, se comete un delito, no es pertinente responsabilizar penalmente a la persona jurídica. El órgano de vigilancia

58 DOPICO GÓMEZ-ALLER, J.: Posición de garante del compliance officer por infracción del deber de control: una aproximación tópica, en El Derecho penal económico en la era Compliance (L. Arroyo Zapatero y A. Nieto Martín dirs.), Valencia (Tirant lo Blanch), 2013, pags. 165 y ss.; y, ROBLES PLANAS, R.: El responsable de cumplimiento (compliance officer) ante el derecho penal, en Criminalidad de empresa y Compliance, Prevención y reacciones corporativas (Silva Sánchez, dir.), Barcelona (Atelier), 2013, pags. 319 y ss. 
habría ejercido con suficiencia sus funciones y pese a ello no se pudo evitar el delito.

No obstante, reseñar que esta condición en muchos casos guardará una estrecha relación con la anterior, relativa a la elusión fraudulenta del directivo.

\section{Condiciones si el delito de referencia fue cometido por un subordinado conforme al art. 31 bis 1 b), operan las condi- ciones del art. 31 bis 4}

En los casos en que el delito de referencia ha sido cometido por un subordinado el Código Penal solo exige la condición de idoneidad para que el programa de cumplimiento despliegue eficacia eximente o atenuante. Por tanto, en el hecho de conexión descrito en el art. 31 bis 1 b), la exención o atenuación de responsabilidad penal únicamente requiere que el juez compruebe una única condición.

No obstante, la doctrina mayoritaria sostiene que aunque solo se requiere explícitamente esta condición de idoneidad, en realidad, implícitamente también se precisa la concurrencia de las demás condiciones exigidas en el art. 31 bis 2 , excepto la de "elusión fraudulenta" del art. 31 bis $2,3^{\mathrm{a}} \mathrm{CP}^{59}$.

Desde luego esta exigencia implícita resulta claramente extensible a la exigencia de adopción y ejecución de un programa "por la persona jurídica", que completa la condición de idoneidad. Ello, porque aunque aquí utilice la expresión "persona jurídica" y en el apartado $2,1^{a}$ la de "órgano de administración", ambos términos son de todo punto equivalentes. En realidad en los dos apartados debería decir "órgano de administración de la persona jurídica". En un caso es obvio que "órgano de administración" va referido a "persona jurídica". Y en el otro, que la "persona jurídica" adopta y ejecuta sus acuerdos a través de su "órgano de administración".

59 Por todos, LEÓN ALAPONT, J.: “Criminal Compliance: análisis ...”, cit. pags. 22 y 23. 
También parece lógico exigir la condición $2^{\mathrm{a}}$ del apartado 2 del art. 31 bis, consistente en haber confiado a un órgano de la persona jurídica poderes de supervisión del funcionamiento y cumplimiento del programa. En efecto, porque si la sociedad alega poseer medidas idóneas, éstas han de estar comprendidas en un programa de cumplimiento. Y éste debe haberse aprobado y ejecutado por un órgano con poderes autónomos. Es decir, no puede hablarse de medidas idóneas si no existe un programa y un órgano de cumplimiento del mismo. A esta conclusión se llega igualmente desde una interpretación sistemática con los "requisitos" exigidos en el art. 31 bis 5 CP.

Otra cosa distinta es la clase de órgano de cumplimiento aquí exigido, pues además de comprender todos los posibles conforme a lo expuesto en relación al apartado 2, $2^{\mathrm{a}}$ del art. 31 bis $\mathrm{CP}$, aquí debe añadirse lo previsto especialmente para "personas jurídicas de pequeñas dimensiones" del art. 31 bis $3 \mathrm{CP}$. Es decir, que estos poderes recaigan directamente en el propio órgano de administración. De suerte que, la dispensa de poseer un órgano de cumplimiento con poderes autónomos respecto del consejo de administración, se aplica en sociedades de "pequeñas dimensiones" tanto si el delito de referencia fue cometido por un representante, administrador o directivo (primer hecho de conexión), como si lo fue cometido por un subordinado (segundo hecho de conexión).

Más discutible es trasladar a este supuesto la condición $4^{\mathrm{a}}$ del apartado 2 del art. 31 bis, que dice: "no se ha producido una omisión o ejercicio insuficiente de sus funciones de supervisión, vigilancia y control por parte del órgano al que se refiere la condición $2^{a}$ ", esto es, del órgano dotado de funciones de supervisión del funcionamiento y del cumplimiento del programa. A este respecto la duda estriba en que nos encontramos en el segundo hecho de conexión, donde el delito es cometido por un subordinado. Y justamente este segundo hecho de conexión se define literalmente en referencia a que cualquiera de los subordinados "han podido realizar el hecho por haberse incumplido 
gravemente por aquéllos los deberes de supervisión, vigilancia $y$ control de su actividad". Es decir, que el propio hecho de conexión consiste en un incumplimiento grave de los deberes de vigilancia por parte de cualquiera de los órganos unipersonales o colegiados dotados de esos poderes. Y entre estos órganos todos estamos de acuerdo, sin duda alguna, que se encuentra el órgano de cumplimiento. En consecuencia resulta reiterativo e innecesario valorar dos veces el mismo concepto, primero como integrante del hecho de conexión y después como condición para eximir o atenuar. Podría decirse que el incumplimiento es inherente al régimen legal de delitos cometidos por subordinados. Esta interpretación se refuerza con la exigencia en el hecho de conexión de subordinados que el incumplimiento sea "grave". De suerte que, si éste no alcanza esta magnitud no habrá siquiera transferencia de responsabilidad a la persona jurídica y por tanto no habrá lugar a plantear una eximente o atenuante ${ }^{60}$.

La única alternativa para compartir la postura de la doctrina mayoritaria sería romper la identificación entre los las fórmulas "haberse incumplido gravemente por aquéllos los deberes de supervisión, vigilancia y control de su actividad", del segundo hecho de conexión, y, "no se ha producido una omisión o ejercicio insuficiente de sus funciones de supervisión, vigilancia y control por parte del órgano al que se refiere la condición $2^{a}$ "contenidos en la condición $4^{\mathrm{a}} \mathrm{del}$ apartado 2 . Esto es, mantener que se trata de funciones diferentes en uno y otro pasaje del texto legal.

Esta tesis es defendida por GALÁN MUÑOZ, quien sutilmente apunta que el incumplimiento del deber de supervisión, vigilancia y control, del art. 31 bis 2, 4, "no está específicamente referido a concretas conductas ajenas, como sucede con el de la letra b) del primer apartado de dicho artículo (la de los subordinados) ni a concretas medidas preventivas referidas a las mismas, sino al funcionamiento y cumplimiento general

60 LEÓN ALAPONT, J.: La responsabilidad penal de los partidos politicos... cit., pags.322 y ss. 
de las medidas preventivas establecidas y contempladas por el modelo". A lo que añade otra diferencia más en el régimen legal, precisamente la que se refiere a la exigencia de "gravemente", contenida en el hecho de conexión de los subordinados, pero no en la condición precisada para eximir o atenuar en el caso del incumplimiento de los dirigentes. Esto último le lleva con razón a considerar que cualquier clase de incumplimiento en este caso, ya sea grave o leve, impedirá la apreciación de la citada condición cuarta del apartado segundo ${ }^{61}$.

En todo caso, requerir para el segundo hecho de conexión las mismas condiciones para eximir o atenuar la responsabilidad penal que las expresamente previstas para el primer hecho de conexión, no solo resulta forzado, sino probablemente contrario al fundamento legal desde el que se regulan los dos modelos de conexión ${ }^{62}$.

Pues bien, en relación ya con la singularidad de la definición de la condición de idoneidad, el texto señala: "Si el delito fuera cometido por las personas indicadas en la letra b) del apartado 1, la persona jurídica quedará exenta de responsabilidad si, antes de la comisión del delito, ha adoptado y ejecutado eficazmente un modelo de organización y gestión que resulte adecuado para prevenir delitos de la naturaleza del que fue cometido o para reducir de forma significativa el riesgo de su comisión".

Esta condición de idoneidad también aquí se desdobla en tres: idoneidad temporal; idoneidad formal e idoneidad material. Las dos primeras se formulan exactamente igual que para representantes, administradores y directivos, por lo que nos remitimos a lo expuesto allí. En efecto, porque el texto reclama que el programa de cumplimiento haya sido adoptado y ejecutado "antes de la comisión del delito" (condición de idoneidad

61 GALÁN MUÑOZ, A.: Fundamentos y limites de la responsabilidad penal de las personas jurídicas..., cit. pags. 156 a 158.

62 GALÁN MUÑOZ, A.: Fundamentos y límites de la responsabilidad penal de las personas jurídicas..., cit. pags. 174 y 175. 
temporal). Y que el programa de cumplimiento resulte adecuado para prevenir "delitos de la misma naturaleza del que fue cometido" (condición de idoneidad formal). La única diferencia en su formulación literal reside en la condición de idoneidad material, que paso a desarrollar.

Como en la condición descrita en el art. 31 bis $2,1^{\mathrm{a}}$, en este apartado 4 la condición de idoneidad material se formula con dos alternativas. La primera requiere que el modelo "resulte adecuado para prevenir delitos de la naturaleza del que fue cometido". Aquí se observa un término distinto, al usar "adecuado para prevenir" en relación al programa, en lugar de "idóneas para prevenir" en relación a las medidas contenidas en el programa de cumplimiento. En cuanto a la segunda alternativa, coincide con exactitud con la del art. 31 bis 2, 1": "o para reducir de forma significativa el riesgo de su comisión". Así pues, respecto a esta última nos remitimos a lo expuesto con anterioridad.

Aquí ya no habla de idoneidad para prevenir o para reducir de forma significativa el riesgo de su comisión, sino solamente que resulte adecuado para prevenir o reducir. Esta diferente redacción abre dos posibles exégesis. La primera que "adecuado" se interprete como sinónimo de "idoneidad". Y la segunda sostener que poseen diferentes significados, otorgando al término "adecuado" una entidad más débil, esto es, una suerte de rebaja del estándar de exigencia. Por esta última solución me incliné en el primer trabajo sobre la materia ${ }^{63}$. Pero ahora he de rectificar esta tesis y proponer un entendimiento unitario de "idóneas" y "adecuado". Ello porque en el uso común del lenguaje ambos términos poseen idéntico significado, en el sentido de apto, apropiado, capacitado para prevenir o reducir. De ahí que también en este punto me remita a lo ya expuesto con anterioridad.

Sin embargo el cambio de criterio requiere una breve explicación. La interpretación asimétrica propuesta inicialmente

63 GONZÁLEZ CUSSAC, J. L.: Responsabilidad penal de las personas jurídicas (arts. 31 bis, ter, quater y quinquies), cit. pags. 190 a 194. 
se sustentaba en que, de la diferente posición que ocupan de una parte representantes, administradores y directivos, y de otra los subordinados, se derivaba un diferente tratamiento jurídico. Entonces quise referenciar este diferente régimen jurídico en el uso del término "adecuado", otorgándole un sentido más restrictivo que a idóneo. Con ello buscaba ser fiel al doble fundamento y consiguiente dual tratamiento de la responsabilidad criminal de la persona jurídica en consideración a la persona natural que comete el delito de referencia. Así, una mayor exigencia si se origina en un delito cometido por representante, administrador o directivo, y una gravedad menor si el delito fue cometido por un subordinado. Es decir, apelaba a una justificación sustantiva.

Pero tras una lectura más detenida, este doble régimen ya se contiene en la diferente formulación de los dos hechos de conexión y también en el distinto listado de condiciones. Por tanto no es necesario forzar el sentido literal de "adecuado" para plasmar esta asimetría que ya se expresa en otros lugares de la regulación legal.

La más significativa de las diferencias conecta ambos momentos, hecho de conexión y condiciones, y se halla directamente anudada a la idea de "debido control". En efecto, porque en la misma descripción del hecho de conexión de subordinados se requiere expresamente que "han podido realizar los hechos por haberse incumplido gravemente por aquéllos los deberes de supervisión, vigilancia y control atendidas las concretas circunstancias del caso". De modo que la infracción del debido control pertenece al propio hecho de conexión. Es decir, si no se demuestra la infracción grave de los deberes de vigilancia y control no puede operarse la transferencia de responsabilidad a la sociedad.

Por el contrario, en el caso de representante, administrador o directivo, su hecho de conexión no menciona siquiera esta categoría. De suerte que, la transferencia de responsabilidad entra en juego directamente, sin que el juez tenga todavía que examinar la infracción del debido control. Para encontrar esta 
referencia, en el modelo legal español tenemos que esperar a un momento posterior. Este momento posterior se halla en la condición contenida en el art. 31 bis $2,4^{\text {a }}$ : que no se haya producido una omisión o ejercicio insuficiente de las funciones de supervisión, vigilancia y control.

En todo caso resultan de gran interés los interrogantes que plantea GALÁN MUÑOZ: “'realmente el derecho penal puede fundamentar la responsabilidad de la entidad (...), atendiendo a la realización de un juicio hipotético referido a lo que podría y debería haber acaecido y no a lo que realmente sucedió?" ${ }^{64}$. En opinión del citado autor, la medición de la idoneidad en los supuestos de subordinados, debe verificarse conforme a tres pasos consecutivos. En el primero, si la medida resulta ex ante idónea para disminuir el riesgo de comisión de delitos como el efectivamente cometido. Segundo, que, desde un punto de vista ex post, el riesgo no permitido derivado de la infracción del superior se materialice efectivamente en el concreto delito cometido por el subordinado. Y, tercero, la aportación causal derivada de la infracción del riesgo preventivo del superior ha de revestir una magnitud que permita considerarla como necesaria para que dicho delito se hubiera cometido.

En resumen, el Código Penal español dispone un diferente régimen jurídico de responsabilidad criminal de la persona jurídica. Lo hace en consideración a la diferente posición jurídica ostentada de una parte por representantes, administradores y directivos, y de otra por subordinados. En esta diferente posición se encuentra el fundamento del doble régimen jurídico. Y la expresión más elocuente de esta asimetría se encuentra en el análisis en dos planos diversos, y por tanto también en dos momentos diferentes, del debido control.

64 GALÁN MUÑOZ, A.: Fundamentos y limites de la responsabilidad penal de las personas jurídicas..., cit. pag. 167. 


\section{Condiciones si se trata de empresas de pequeñas dimen- siones (art. 31 bis 3)}

Para su conceptuación se prevé una definición legal de esta clase de persona jurídica: "A estos efectos, son personas jurídicas de pequeñas dimensiones aquéllas que, según la legislación aplicable, estén autorizadas a presentar cuenta de pérdidas y ganancias abreviada".

En estos casos, la especialidad reside en que "las funciones de supervisión a que se refiere la condición $2 .{ }^{a}$ del apartado 2 podrán ser asumidas directamente por el órgano de administración".

Pues bien, el legislador también incluye en el modelo del art. 31 bis y siguientes a las pequeñas empresas, de modo que pueden adoptar programas de cumplimiento, y consiguientemente éstos puedan tener una eficacia eximente o atenuante para la responsabilidad de la sociedad. Ahora bien, les permite que sean supervisados directamente por el administrador. Esta es la única diferencia formal que les dispensa.

La especialidad está plenamente justificada. Es decir, existen razones económicas, estructurales y de tamaño para no exigir un incremento de los costes originado en la necesidad de dotarse de modelos de cumplimiento. Igualmente convergen razones de índole jurídico, como su sometimiento a regímenes fiscales, administrativos y mercantiles diferenciados ${ }^{65}$.

65 Por ejemplo, el art. 258 de la Ley de Sociedades de Capital establece en su apartado primero que: "Podrán formular cuenta de pérdidas y ganancias abreviada las sociedades que durante dos ejercicios consecutivos reúnan, a la fecha de cierre de cada uno de ellos, al menos dos de las circunstancias siguientes: a) Que el total de las partidas de activo no supere los once millones cuatrocientos mil euros. b) Que el importe neto de su cifra anual de negocios no supere los veintidós millones ochocientos mil euros. c) Que el número medio de trabajadores empleados durante el ejercicio no sea superior a doscientos cincuenta. Las sociedades perderán la facultad de formular cuenta de pérdidas y ganancias abreviada si dejan de reunir, durante dos ejercicios consecutivos, dos de las circunstancias a que se refiere el párrafo anterior". 
El resto del modelo legal se aplica exactamente igual, vinculando cada uno de los dos hechos de conexión con su respectivo haz de condiciones.

\section{Naturaleza jurídica de las condiciones y la cuestión de la carga de la prueba}

La naturaleza jurídica de las condiciones ha desatado una aguda controversia que, transcendiendo el ámbito del Derecho penal sustantivo, ha alcanzado su punto culminante en una importante discusión procesal con contenido constitucional. Así, según la diferente naturaleza jurídica de las condiciones, se deriva directamente una $u$ otra posición en materia de carga de la prueba. En este debate participan significativamente tanto la Sala Segunda del Tribunal Supremo como la Fiscalía General del Estado ${ }^{66}$.

Este debate se inscribe en otro más amplio y clásico como es el de la carga de la prueba de las eximentes ${ }^{67}$.

Para llegar a este nivel de discusión, muchos autores previamente recurren a la búsqueda del fundamento de todo el sistema de responsabilidad penal de la persona jurídica. De modo que, el punto de partida lo constituye el fundamento del modelo, que a su vez determina seguidamente la naturaleza jurídica de las condiciones y sucesivamente también fija los estándares probatorios. Sin embargo, tal reducción no resulta exacta del todo y requiere algunos matices. Procederé a su exposición agrupando las posturas no desde el criterio del fundamento del modelo o de la naturaleza de las condiciones, sino desde la posición en materia de carga de la prueba.

66 Una precisa exposición y crítica de todas las posturas doctrinales y jurisprudenciales puede verse en GALÁN MUÑOZ, A.: Fundamentos y límites de la responsabilidad penal de las personas jurídicas... cit., especialmente en pags. 80 y ss.

67 CUERDA RIEZU, A.: "La prueba de las eximentes en el proceso penal: ¿obligación de la defensa o de la acusación?”, InDret, num. 2, 2014, pp. 1 y ss. 
De forma muy simple se podría decir que existen tres grandes posturas al respecto.

\subsection{La carga de la prueba corresponde a la defensa.}

Esta solución se defiende desde dos diferentes concepciones del fundamento del modelo de responsabilidad criminal de la persona jurídica, pero que sin embargo parecen coincidir que las condiciones poseen idéntica naturaleza de eximentes.

A) Los que, partiendo de una concepción vicarial, de heterorresponsabilidad o transferencia, no muestran una preocupación por construir estructuras de imputación reflejas de la teoría jurídica del delito en sede de responsabilidad penal de las personas jurídicas. Se contentan con la exigencia de los requisitos legales y que su aplicación se desarrolle conforme a parámetros constitucionales. Si se quiere, esta sería la posición defendida en este trabajo ${ }^{68}$. En este sentido, de la lectura literal del texto legal se infiere que las condiciones son equivalentes a las "eximentes". Consecuentemente la carga de la prueba como poco debe ser compartida entre acusación y defensa, aunque como generalmente será esta última la que la aduce, el impulso y mayor peso probatorio recaerá sobre ella. Por consiguiente, quien alega que una sociedad posee un programa eficaz deberá soportar la carga de la prueba, que como se recordará, consiste en demostrar las diferentes condiciones exigidas para cada uno de los dos hechos de conexión. Así, si la sociedad alega en el proceso penal que ha adoptado y ejecutado un programa de cumplimiento, le corresponderá a ella acreditar su idoneidad. En palabras de la Fiscalía

68 En similar línea, entre otros, DEL ROSAL BLASCO, B.: "Sobre los elementos estructurales de la responsabilidad penal de las personas jurídicas... ", cit; RODRÍGUEZ RAMOS, L.: "Sobre la culpabilidad de las personas jurídicas", Diario La Ley, $\mathrm{n}^{\circ}$ 8766, 2016; LEÓN ALAPONT, J.: “Criminal Compliance: análisis ....", cit. LEÓN ALAPONT, J.: “La responsabilidad penal de los partidos politicos", cit. pags. 515 y ss.. Muy cercana a esta línea ROBLES PLANAS, R.: “El 'hecho propio'de las personas jurídicas y el Informe del Consejo General del Poder Judicial al Anteproyecto de Reforma del Código Penal de 2008”, InDret, n 2, 2009. 
General del Estado, se trataría de "causas personales de exclusión de la punibilidad" ${ }^{6}$.

B) A esta misma conclusión también llegan quienes muestran una preocupación por extender las categorías dogmáticas de la teoría jurídica del delito en sede de responsabilidad de la persona moral. A tal efecto diferencian entre los elementos que integrarían la imputación objetiva, coincidentes con lo que aquí hemos denominado "presupuestos comunes" y "hechos de conexión". Y de otra parte, consideran el "defecto de organización" como equivalente a una culpabilidad propia de la persona jurídica. De modo que, la imputación subjetiva de la responsabilidad penal de la persona moral radicará en la ausencia de medidas eficaces para evitar la comisión de delitos o para reducir el riesgo de su comisión. El reproche a la sociedad expresa un "defecto de organización" por su negligencia al no haber adoptado medidas eficaces o no haberlo hecho suficientemente. Consecuentemente con esta construcción, las condiciones poseen naturaleza de causas de inculpabilidad y por ende son equivalentes a las eximentes ${ }^{70}$. En resumen, también desde un entendimiento como modelo de autorresponsabilidad se llegaba a la misma conclusión en materia de la carga de la prueba.

69 Esta es la postura contenida en la Circular 1/2016, de la Fiscalía General del Estado

70 Entre otros, puede verse ZUGALDÍA ESPINAR, J. M.: La responsabilidad criminal de las personas jurídicas en el derecho penal español (análisis de la cuestión tras la reforma operada por la LO 1/2015, de 30 de marzo), en ZUGALDÍA ESPINAR, J. M. Y MARÍN DE ESPINOSA CEBALLOS, E. B. (Dir.): La responsabilidad criminal de las personas jurídicas en Latinoamérica y en España, Pamplona (Thomson-Aranzadi), 2015, pag. 223; DE LA MATA BARRANCO, N. J.: La actuación conforme a protocolos de prevención de delitos como causa de exención de responsabilidad penal, en DE LA CUESTA ARZAMENDI, J. L. (Dir.): Responsabilidad Penal de las Personas Jurídicas, Pamplona (Cizur Menor, Thomson Reuters-Aranzadi), 2013, pag 253; FERNÁNDEZ TERUELO, J.: Regulación vigente: exigencias legales que permiten la atribución de responsabilidad penal a la persona jurídica y estructura de imputación (CP art. 31 bis 1, 2 inciso $1^{\circ} y$ $5^{\circ}$ ), en JUANES PECES, Á. (Dir.): Responsabilidad penal y procesal de las personas jurídicas, Madrid (Francis Lefebvre), 2015, pag. 79. 
Refuerza esta interpretación que solo la empresa puede acometer la comprobación de la idoneidad de su programa por cuanto es la única que posee toda la información ${ }^{71}$.

\subsection{La carga de la prueba corresponde a la acusación}

Una segunda línea interpretativa parte de un entendimiento del modelo en clave de hecho propio y de culpabilidad propia de la persona jurídica (autorresponsabilidad). Esta construcción sucintamente se estructura en un injusto propio de la persona moral relativo al defecto de organización, y en una culpabilidad propia consistente en una cultura del incumplimiento de la legalidad ${ }^{72}$.

De aquí infieren que las condiciones exigidas para medir la idoneidad preventiva, o más exactamente, que los programas en su totalidad, se configuran como elementos del tipo de la responsabilidad propia de la empresa. Desde este entendimiento niegan su naturaleza de eximentes o de causas personales de exclusión de la punibilidad ${ }^{73}$. Consecuentemente con este plantea-

71 Argumenta y desarrolla esta tesis con múltiples argumentos constitucionales, técnico-jurídicos y prácticos GÓMEZ TOMILLO, M.: "Responsabilidad penal de las personas jurídicas y carga de la prueba de la idoneidad de los programas de cumplimiento", La Ley núm. 8522, 2016; del mismo: Programa de cumplimiento penal y política legislativa, Valencia (Tirant lo Blanch), 2016, pags. 32 y ss.

72 Su principal impulsor es GÓMEZ-JARA DÍEZ, C. y puede verse entre otras obras en: Fundamentos de la responsabilidad penal de las personas jurídicas, y El injusto típico de la persona jurídica (tipicidad), ambos en BAJO FERNÁNDEZ, M.; FEIJÓO SÁNCHEZ, B. y GÓMEZ-JARA DÍEZ, C.: Tratado de responsabilidad penal de las personas jurídicas, Pamplona (Cizur Menor, Thomson Reuters-Aranzadi), 2016, respectivamente pags. 105 y ss.; y 128. En un sentido muy coincidente FEIJÓO SÁNCHEZ, B.: Las consecuencias jurídicas del delito, en BAJO FERNÁNDEZ, M.; FEIJÓO SÁNCHEZ, B. y GÓMEZ-JARA DÍEZ, C.: Tratado de responsabilidad penal de las personas jurídicas, Pamplona (Cizur Menor, Thomson ReutersAranzadi), 2016, p. 278 y ss.

73 FEIJÓO SÁNCHEZ, B.: El delito corporativo en el Código penal español, cit. pags. 177 y ss.; del mismo: "Réplica a Javier Cigüela. A la vez algunas consideraciones sobre las últimas novedades en materia de responsabilidad penal de las personas jurídicas: Circular de la Fiscalia General del Esta- 
miento, la carga de la prueba no puede recaer sobre la defensa, y entonces a la acusación corresponderá probar que la empresa no poseía un programa de cumplimiento eficaz ${ }^{74}$.

Obsérvese que esta exégesis entiende que el presupuesto o tipo de la responsabilidad penal de la persona jurídica está también integrado por un requisito en cierto modo negativo: no poseer un programa de cumplimiento eficaz. Por ello algunos autores hablan de su comprensión como "elementos negativos del tipo".

También encontramos autores que simplemente aducen que la probatio diabólica se produciría si fuera la defensa la que tuviera que cargar con la prueba de que no hubo un defecto de organización ${ }^{75}$.

\subsection{Tesis "conciliadora"}

También podría decirse que circula una suerte de tesis de compromiso, ecléctica o conciliadora entre ambas posturas. Esta tesis mixta se levanta desde la diferente consideración de los dos hechos de conexión. Así, distingue si el delito ha sido cometido por representante, administrador o directivo, o si por el contrario fue cometido por un subordinado. En el primer caso el régimen de las condiciones se acercaría al de las eximentes y consecuentemente la carga de la prueba recaería generalmente en quien lo alegue, es decir, en la empresa. Mientras que, en el segundo supuesto, subordinados, el cumplimiento de las condiciones, y con ello la eficacia del compliance, se asemejaría a un

do 1/2016 y Sentencia del Tribunal Supremo 154/2016, de 29 de febrero y 221/2016, de 16 de marzo", InDret, no 2, 2016.

74 Esta es la tesis sostenido por la mayoría en la STS 154/2016, de 29 de febrero. Advertir que, aunque se trata de una sentencia de Pleno, solo ocho de los 15 magistrados la suscriben, formulándose siete votos particulares, todos precisamente por discrepar en la cuestión aquí expuesta.

75 GÓMEZ MARTÍN, V. Falsa alarma. O sobre por qué la LO 5/2010 no deroga el principio societas delinquere non potest, en Garantias penales $y$ derecho penal europeo (S. Mir Puig y M. Corcoy Bidasolo, Directores), Madrid (Marcial Pons), 2-12, pag. 252. 
requisito integrante de la tipicidad, de suerte que su acreditación corresponderá siempre a la acusación.

A similares resultados se llega también desde otro planteamiento, aunque en el fondo conserva idénticas premisas. Así, se propone conciliar la primera y segunda propuesta, una defendida por la Circular 1/2016 de la FGE y la otra por la mayoría de magistrados en la Sentencia de Pleno 154/2016, diferenciando entre un cotejo de la eficacia de las medidas en relación al delito cometido, y otro global del conjunto del programa. De modo que, si el análisis se limita a la eficacia de las medidas adoptadas en relación al delito de referencia, corresponde a la acusación demostrar su ineficacia en el caso concreto. Por el contrario, si el examen de idoneidad se proyecta sobre la totalidad del programa de cumplimiento, corresponderá a la defensa su demostración. Para ello se aduce que en este segundo caso, solo la empresa está en posesión de toda la información necesaria para efectuar un análisis global ${ }^{76}$.

\section{Dogmática, Ley y Constitución}

Pues bien, en este debate lo que más me sorprende es que un problema con relevancia constitucional se resuelva desde un dogma. Desde luego no me parece adecuada esta vía ni por tanto determinantes las conclusiones que se alcancen. Porque por muy fructífera que sea la creatividad del intérprete, lo decisivo no es lo que cada uno crea, piense o considere mejor, más deseable o acomodado a tendencias, presupuestos o fundamentos materiales. A mi juicio en Derecho penal, incluida la temática que nos ocupa, rige el sistema de fuentes que obliga a una interpretación conforme al texto de la ley.

Sin duda merece elogio la gran preocupación de la Sala Segunda del Tribunal Supremo por una aplicación del novedoso

76 En este sentido GÓMEZ DÍEZ-JARA, C.: El Tribunal Supremo ante la responsabilidad Penal de las Personas Jurídicas..., cit. pags. 87 a 92. 
modelo de responsabilidad criminal de la persona jurídica conforme al sistema de derechos y garantías constitucionales. En esto estamos todos de acuerdo ${ }^{77}$. Y esta loable preocupación, insisto, es compartida por todos. Y en efecto, es la línea seguida por varias resoluciones inmediatamente posteriores a la citada.

Pero en realidad la STS 154/2016 fue mucho más lejos de esta meta. Primero porque sentó una doctrina sustantiva que en absoluto estaba consensuada. Segundo, porque no era necesario formularla en el caso enjuiciado. Tercero, porque incurre en la inversión metodológica antes descrita: de un dogma material se infiere todo el régimen jurídico, incluido el constitucional. Cuarto, porque su doctrina no deriva del texto de la ley, sino de una concepción dogmática previa. Quinto, porque los dogmas en los que fundamenta la responsabilidad, especialmente la noción "cultura de cumplimiento de la legalidad", es sumamente vaporoso y aboca a la incerteza de su contenido. Sexto, porque en materia de prueba y carga de la prueba en materia de eximentes ya existe una doctrina muy consolidada. Y séptimo, porque con el pretendido objetivo de salvaguardar garantías constitucionales paradójicamente se llega a un extremo difícilmente conciliable con las mismas. Esto es obvio, como suscriben los votos particulares, en lo relativo a la prueba de hechos negativos y a la llamada prueba diabólica ${ }^{78}$. Por todo lo anterior, comparto el parecer expresado en los citados votos particulares emitidos en la STS 154/2016, y muy especialmente sus razonamientos constitucionales acerca de la presunción de inocencia y lógicos sobre la trasmutación en una prueba diabólica la carga a la acusación de demostrar hechos negativos.

77 Ya en la STS 514/2015, de 2 septiembre, se advertía que "ya se opte por un modelo de responsabilidad por el hecho propio, ya por una fórmula de heterorresponsabilidad parece evidente que cualquier pronunciamiento condenatorio de las personas jurídicas habrá de estar basado en los principios inrrenunciables que informan el derecho penal".

78 En sentido coincidente con el mantenido en el texto, DEL ROSAL BLASCO, B.: "Sobre los elementos estructurales de la responsabilidad penal de las personas jurídicas...", cit. 
Por las mismas razones tampoco comparto algunos de los razonamientos que sustentan la anterior resolución, en parte recogidos en la STS 516/2016, de 13 de junio. En concreto, no comparto que los presupuestos y hechos de conexión legalmente fijados en el art. 31 bis CP se reduzcan al delito cometido por una persona física. Si así fuera, que no lo es, naturalmente estaríamos en un escenario de responsabilidad vicarial.

Como ya expuse al comienzo de este trabajo, el modelo legal español no configura un sistema vicarial puro que si podría poner en jaque exigencias constitucionales. El art. 31 bis $\mathrm{CP}$ no establece una transferencia directa y automática de responsabilidad penal desde el delito cometido por una persona natural hasta la persona jurídica. Como ya vimos requiere de unos presupuestos comunes y de dos diferentes hechos de conexión, cada uno con sus requisitos. Este conjunto de exigencias positivas es lo que legitima legalmente el castigo a la sociedad. Por tanto, como ya he desarrollado en otros trabajos ${ }^{79}$, no encuentro déficit constitucional en esta regulación legal. De modo que, esta regulación positiva es la que hay que aplicar, no necesitando recurrir a criterios materiales metalegales para su interpretación.

En definitiva, el texto legal contiene un régimen bastante sencillo: la responsabilidad criminal de la sociedad se sustenta en la comprobación de unos presupuestos y de uno de los dos hechos de conexión. Y a partir de aquí, entra en juego un segundo plano, equivalente al sistema de eximentes y atenuantes. Además, este segundo plano solo entrará en juego si la sociedad alega poseer un programa de cumplimiento. Entonces el juez debe comprobar que reúne las condiciones requeridas legalmente para desplegar su eficacia eximente o atenuante. Es más, el propio texto legal utiliza estas expresiones: eximir y atenuar

79 GONZÁLEZ CUSSAC, J. L.: El plano constitucional en la responsabilidad penal de las personas jurídicas, en Represión Penal y Estado de Derecho. Libro Homenaje al Profesor Gonzalo Quintero Olivares (F. Morales Prats; J. Ma . Tamarit Sumalla; R. García Albero, coordinadores), Pamplona (Aranzadi), 2019, pags. 565 a 576 . 
como el efecto jurídico de las condiciones. Es más, incluso se refiere a las condiciones como "circunstancias".

En este contexto tampoco comparto el argumento de FEIJOÓ SÁNCHEZ, favorable al entendimiento de los programas como elementos de la tipicidad, sustentado en que el art. 31 bis habla de "exención de la responsabilidad penal" y no simplemente de "exención de la pena" ${ }^{\circ 0}$. Primero, porque idéntica expresión es la empleada tanto en la rúbrica del Capítulo II del Título I, como en el art. $20 \mathrm{CP}$. Y segundo, porque con estos mismos términos legales referidos a la responsabilidad criminal de la persona física nadie cuestiona su naturaleza/eficacia de eximentes, a la vez que admite un doble fundamento: en unos casos como causas de justificación y en otros como excusas (inculpabilidad). De suerte que, no acabo de ver la razón de romper esta expresa equivalencia de términos legales entre los arts. 20 y 31 bis CP.

También discrepo del siguiente razonamiento de la STS 516/2016, de 13 de junio, que dice: "La Sala no puede identifcarse con la tesis de que en el sistema español pueda hablarse de una responsabilidad penal de las personas jurídicas, pero no de un delito de las personas jurídicas. No hay responsabilidad penal sin delito precedente. Lo contrario abriría una peligrosísima vía con efectos irreversibles en los fundamentos mismos del sistema penal". En primer lugar, porque sí hay un delito precedente, justamente el cometido por una persona física de las enumeradas en el art. 31 bis. Segundo, porque no se puede identificar "cometer" un delito y ser responsable del mismo. Esta cuestión nos adentraría en una compleja y vieja discusión doctrinal sobre lo que ha de entenderse por "realización" de los actos típicos y con ello en la discusión general sobre autoría y participación $^{81}$.

80 FEIJÓO SÁNCHEZ, B.: “Réplica a Javier Cigüela...” cit., pag. 28.

81 Por ejemplo, sobre la cuestión, MIR PUIG, S.: Derecho Penal. Parte General, $9^{a}$ edición, Barcelona (Reppertor9, 2011, pags. 382 y ss. 
En efecto, como ya sostuvo VIVES ANTÓN, no es lo mismo "cometer" o "realizar" el hecho que "ejecutar la acción". Esta segunda expresión posee un significado mucho más estricto y equivale a materializar la acción, a "ponerla por obra", es decir, se circunscribe a la autoría en sentido estricto. Por el contrario, "realizar o "cometer" son términos más amplios y difusos, que incluyen tanto las modalidades de autoría como de participación ${ }^{82}$. Pues bien, de esta distinción se pueden extraer algunas consecuencias interpretativas.

La primera, que el texto legal emplea "cometer" el delito por una persona física. De lo que se deriva que no necesariamente se limita a actos materiales de autoría de la persona física, sino que también puede incluir ciertas hipótesis de participación de ésta.

Es decir, como una forma de extensión de la punibilidad habilitada mediante el recurso a la técnica de una cláusula legal expresa, en este caso el art. 31 bis CP. Este entendimiento del fundamento de la responsabilidad penal de la persona jurídica guardaría cierto parentesco con la justificación ofrecida al castigo de las personas físicas por asociación ilícita o pertenencia a una organización criminal. Esto es, se apoya en los modelos de atribución de responsabilidad penal a los miembros de organizaciones criminales. Por ejemplo, en la propuesta de SILVA SÁNCHEZ de "coparticipación" como figura paralela a la coautoría y que parte de la "teoría de la anticipación". Así, la responsabilidad penal se sustentaría en su propia actividad favorecedora del hecho concreto realizado ${ }^{83}$. De este modo se logra determinar y vincular el castigo a la lesividad del delito concreto

82 VIVES ANTÓN, T. S.: Libertad de prensa y responsabilidad criminal (la regulación de la autoría en lo delitos cometidos por medio de la imprenta), Madrid (Publicaciones del Instituto de Criminología de la Universidad Complutense), 1977, p. 160.

83 SILVA SÁNCHEZ, J. M.: La intervención A través de una organización. ¿Una forma moderna de participación en el delito?, en Cancio Meliá, M. y Silva Sánchez, J. M.: Delitos de organización, Montevideo-Buenos Aires (B de F) 2008, pp. 98 y ss. 
por una referencia propia. Desde estos postulados podrían trasladarse esos criterios allí expuestos para explicar técnicamente el modelo legal español. Desarrollo que aquí únicamente me limito a apuntar.

Es más, aunque el texto atribuyera la posibilidad de "cometer" un delito a una persona jurídica, no necesariamente lo tendría que hacer a título de autoría o ejecución material de la acción típica. Esta idea ya fue apuntada en la doctrina precisamente en este contexto, al señalar que la expresión "cometer" o realizar" el delito "abarca junto a la producción material y directa del evento, contribuciones de tipo ideal o indirecto, que si se hallan en el ámbito de las posibilidades de las personas morales" $"$.

Y además de lo anterior, pero en este mismo sentido, podría aducirse con matices que en el art. $31 \mathrm{CP}$ se contiene una fórmula en parte inversa a la plasmada en el art. 31 bis CP. Esto es, el castigo a una persona física "que actúe como administrador de hecho o de derecho de una persona jurídica, o en nombre o representación legal o voluntaria de otro, responderá personalmente, aunque no concurran en él las condiciones, cualidades o relaciones que la correspondiente figura de delito requiera para poder ser sujeto activo del mismo, si tales circunstancias se dan en la entidad o persona en cuyo nombre o representación obre". Estos dos artículos presentan un cierto paralelismo cruzado: en el primero se transfiere la responsabilidad penal desde una persona moral hasta una natural, mientras que en el segundo precepto se habilita la operación inversa: la trasferencia de responsabilidad penal desde una persona física hasta una persona jurídica.

Ciertamente con la redacción del art. 31 se contemplan no solo los supuestos de actuaciones en nombre de personas jurídicas, sino también los de actuación de una persona física en nombre de otra persona física.

84 COBO Del ROSAL, M. Y VIVES ANTÓn, T. S.: Derecho Penal. Parte General, Valencia (Universidad de Valencia), 1984, p. 302. 
Sin embargo, el problema más arduo se plantea fundamentalmente en el seno de los delitos especiales, puesto que la condición o cualidad requerida en el tipo concurre en la sociedad, pero no en las personas físicas que actúan en su nombre. De ahí la necesidad conforme a las exigencias del principio de legalidad, de crear una fórmula que permita imputar el tipo a los que actúan en nombre y representación de la sociedad. Esta es precisamente la función que desempeña el art. $31 \mathrm{CP}$, que requiere que el sujeto activo actúe como "administrador de hecho o de derecho" de la sociedad.

La ubicación tan próxima en el sistema legal español entre ambos preceptos, 31 y 31 bis, refuerza esta proximidad estructural. Quizás por ello FEIJOÓ SÁNCHEZ criticó también en este punto a la STS 154/2016, a la que sigue en este razonamiento la aquí comentada STS 516/2016. Su crítica radica en que ambas resoluciones parecen configurar el art. 31 bis como una suerte de tipo penal autónomo del atribuido a la persona física. Es decir, como una especie de "crimen culpae" de la persona jurídica ${ }^{85}$.

En realidad, creo que en este razonamiento judicial vuelve a pesar la preocupación por hallar una legitimación del castigo a la persona moral, aunque la misma no halla "cometido" el delito en el sentido de que no lo ha realizado. Como ya he expuesto, esta preocupación es absolutamente compartida, pero no la solución técnica ofrecida. Así pues, considero posible desarrollar una aplicación conforme a exigencias constitucionales sin el recurso a estas construcciones materiales alejadas del texto del ley.

Por último, en relación a la discusión sobre la prueba de las condiciones y a qué parte procesal corresponde la carga, el texto legal las equipara en su configuración a las circunstancias eximentes y atenuantes. Por consiguiente, debe aplicarse la doctrina general ya existente, consolidada y conocida.

85 FEIJÓO SÁNCHEZ, B.: “Réplica a Javier Cigüela... ” cit., pags. 34 y ss. 